Universidade de Brasília

Instituto de Psicologia - Departamento de Processos Psicológicos Básicos

Programa de Pós-Graduação em Ciências do Comportamento

\title{
AÇÃO NEUROPROTETORA DA SONATA DE MOZART NA APRENDIZAGEM E MEMÓRIA DE RATOS EXPOSTOS À HIPÓXIA CEREBRAL
}

\section{LARICE FEITOSA COSTA}




\section{AÇÃO NEUROPROTETORA DA SONATA DE MOZART NA APRENDIZAGEM E MEMÓRIA DE RATOS EXPOSTOS À HIPÓXIA CEREBRAL}

Dissertação de Mestrado apresentada ao Programa de Pós-Graduação em Ciências do Comportamento, Departamento de Processos Psicológicos Básicos, Instituto de Psicologia, Universidade de Brasília, como requisito à obtenção do Título de Mestre em Ciências do Comportamento - Área de Concentração: Cognição e Neurociências do Comportamento.

Orientadora: Profa. Dra. Vania Moraes Ferreira

Brasília-DF 


\section{AÇÃO NEUROPROTETORA DA SONATA DE MOZART NA APRENDIZAGEM E MEMÓRIA DE RATOS EXPOSTOS À HIPÓXIA CEREBRAL}

Dissertação de Mestrado apresentada ao Programa de Pós-Graduação em Ciências do Comportamento, Instituto de Psicologia, Universidade de Brasília, como requisito para a obtenção do título de Mestre em Ciências do Comportamento.

Aprovada em 14 de Junho de 2016

\section{Banca Examinadora}

Profa. Dra Vania Moraes Ferreira,

Universidade de Brasília

Presidente

Prof. Dr. Luciano Grudtner Buratto

Universidade de Brasília

Membro Interno

Prof. Dr. Diogo Costa Garção

Universidade Federal de Sergipe

Membro Externo

Profa. Dra. Greice Maria Rodrigues de Souza Garcia UNIEURO

Membro Suplente 


\section{AGRADECIMENTOS}

- A Profa. Dra. Vânia Ferreira, minha orientadora, pela oportunidade e confiança depositadas, pela paciência e compartilhamento dos seus ricos conhecimentos.

- Ao Prof. Dr. Luciano Buratto, que sempre se mostrou solicito a ensinar e compartilhar experiências.

- Ao Prof. Dr. Diogo Garção, pela confiança e motivação de sempre, de que tudo é possível com empenho.

- A Profa. Dra. Leonora Viana, pela disposição e participação neste trabalho.

- A Mara, participante ativa desta pesquisa, com toda disposição possível.

- A minha mãe maravilhosa, por me apoiar incondicionalmente e vibrar por mim mesmo quando tudo parece difícil.

- Ao meu noivo Rafael, por me incentivar com suas sábias palavras e exemplo de dedicação e coragem.

- A toda a minha família, meu porto seguro, pelo carinho, pela torcida e pelas orações.

- A todos os colegas e pessoas especiais que conheci em Brasília e pude contar com o apoio e acolhimento.

- Ao Programa de Pós-graduação em Ciências do Comportamento pela oportunidade de desenvolver este estudo.

- A CAPES, pelo apoio financeiro na execução deste trabalho.

- E a Deus, acima de tudo, por seu amor e cuidado, por me oferecer tantas oportunidades e me conceber saúde, coragem e sabedoria. 
"O sucesso nasce do querer, da determinação e persistência em se chegar a um objetivo. Mesmo não atingindo o alvo, quem busca e vence obstáculos, no mínimo fará coisas admiráveis". 


\section{RESUMO}

A hipóxia isquêmica (HI) encefálica desencadeia uma cascata de eventos bioquímicos que podem culminar em uma extensa morte celular, levando aos déficits cognitivos e comportamentais. A exposição à música, por sua vez, tem sido sugerida como efeito neuroprotetor benéfico durante o desenvolvimento do cérebro e para melhorar a capacidades de aprendizagem e memória em ratos. No entanto, as respostas produzidas por esses eventos parecem ser dependentes da fase de desenvolvimento do cérebro. Com isso, o objetivo deste estudo foi investigar o efeito neuroprotetor da Sonata de Mozart na aprendizagem e memória de ratos com e sem HI, em diferentes fases de desenvolvimento do SNC. Para tal, usou-se ratos fêmeas Wistar ( $\mathrm{n}=48$ ), avaliadas no teste da esquiva inibitória do tipo step-down, que foi dividido em três etapas: treino, aprendizagem/memória de curta duração (MCD) e memória de longa duração (MLD). A HI foi induzida nos ratos com nitrito de sódio quando estavam com 3 meses de idade. Foram utilizados 6 grupos experimentais de ratos ( $\mathrm{n}=8 /$ grupo), divididos em G1 (controle), G2 (controle com HI), G3 (música aguda), G4 (música aguda e HI), G5 (música crônica), G6 (música crônica e HI). Os resultados mostraram que os animais controles, quando avaliados de forma sequenciada ao completarem 1, 2, 3 e 4 meses de idade apresentaram um perfil de resposta, cujo efeito foi progressivamente aumentado quando os ratos foram expostos uma vez por mês à Sonata de Mozart, durante $4 \mathrm{~h} / \mathrm{dia} / 4$ dias. Essa resposta foi mantida mesmo com os prováveis danos produzidos pelo nitrito de sódio. Os efeitos mais relevantes dessa etapa experimental ocorrerarm aos 3 e 4 meses de idade. Ao contrário, quando expostos $4 \mathrm{~h} / \mathrm{dia} / 4$ meses, os animais só manifestaram respostas aos 4 meses, que não foi mantida frente à indução da HI. Em resumo, os dados puderam inferir que a exposição à Sonata de Mozart parece ser um fator importante para estimulação à plasticidade neuronal, visto que quando exposta de forma aguda foi possível perceber respostas sugestivas de aprendizagem e memória, mesmo após lesão por hipóxia isquêmica induzida, enquanto a exposição crônica não demonstrou nenhum efeito neuroprotetor contra a lesão. Os achados parecem demonstrar a possibilidade da utilização de uma ferramenta importante para a neuroplasticidade, relevante para o desenvolvimento do cérebro e readaptação neurológica.

Palavras-chave: aprendizagem, isquemia encefálica, memória, neuroplasticidade, Sonata de Mozart. 


\begin{abstract}
The hypoxic ischemic (HI) brain triggers a cascade of biochemical events that may lead to extensive cell death, leading to cognitive and behavioral deficits. Exposure to music, in turn, has been proposed as beneficial neuroprotective effect during brain development and enhance the capacity of learning and memory in rats. However, the responses produced by these events appear to be dependent on the stage of development of the brain. Thus, the aim of this study was to investigate the neuroprotective effect of Mozart's Sonata in learning and memory in rats with and without $\mathrm{HI}$, at different stages of development of the central nervous system. To this end, we used female Wistar rats $(n=48)$ evaluated in a step-down inhibitory avoidance task, which was divided into three stages: training, learning/short-term memory (STM) and long-term memory (LTM). HI was induced in rats with sodium nitrite at 3 months of age. It was used 6 experimental groups of rats $(n=8 /$ group), divided into G1 (control), G2 (control with HI), G3 (acute music), G4 (acute music and HI), G5 (chronic music), G6 (chronic music and HI). The results showed that the control animals, when assessed in sequential manner to complete 1,2, 3 and 4 months of age showed a response that was progressively increased when rats were exposed once a month with Mozart Sonata for $4 \mathrm{~h} / \mathrm{day} / 4$ days. This response was maintained even with the potential damage produced by sodium nitrite. The most significant effects of this experimental stage was at 3 and 4 months old. Conversely, when exposed $4 \mathrm{~h} / \mathrm{day} / 4$ months, the animals only showed responses at 4 months age, which was not maintained against damage caused by HI. In summary, the data could infer that exposure to Mozart's Sonata appears to be an important factor for stimulating neuronal plasticity, as when exposed acutely it was revealed answers suggestive of learning and memory even after induced HI injury, while chronic exposure showed no neuroprotective effect against injury. These findings seem to demonstrate the possibility of using an important tool to neuroplasticity, relevant to the development of the brain and neurological rehabilitation.
\end{abstract}

Keywords: learning, brain ischemia, memory, neuroplasticity, Mozart Sonata. 


\section{LISTA DE FIGURAS}

Figura 1 - Disposição do aparelho de som e caixas com animais que expostos a Sonata de Mozart..

Figura 2 - Aparelho utilizado no teste de esquiva inibitória do tipo step-down. 22

Figura 3 - Delineamento experimental

Figura 4 - Avaliação da aprendizagem/MCD e MLD de ratos controles no teste da esquiva inibitória, nas idade de 1, 2, 3 ou 4 meses.

Figura 5 - Avaliação da aprendizagem/MCD e MLD de ratos com 1, 2, 3 ou 4 meses, no teste da esquiva inibitória, após receberem a Sonata de Mozart 4h/dia, durante 4 dias que antecediam cada idade.

Figura 6 - Avaliação da aprendizagem/MCD e MLD de ratos com 1, 2, 3 ou 4 meses, no teste da esquiva inibitória após receberem a Sonata de Mozart 4h/diariamente, durante 4 meses

Figura 7 - Avaliação da aprendizagem/MCD e MLD de ratos com 4 meses de idade administrados com NaNO2 aos 3 meses de idade, sem e com exposição à Sonata de Mozart $4 \mathrm{~h} /$ dia, durante 4 dias que antecederam a idade de 4 meses

Figura 8 - Avaliação da aprendizagem/MCD e MLD de ratos com 4 meses de idade administrados com NaNO2 aos 3 meses de idade, sem e com exposição crônica à Sonata de Mozart 4h/dia, durante 4 meses. 28 


\section{LISTA DE ABREVIATURAS}

ANOVA

Análise de Variância

ECG Eletroencefalograma

EM Efeito Mozart

HI Hipóxia Isquêmica

MCD Memória de Curta Duração

MLD Memória de Longa Duração

$\mathrm{NaNO} 2$ Nitrito de sódio

SNC Sistema Nervoso Central 


\section{SUMÁRIO}

1. INTRODUÇÃ

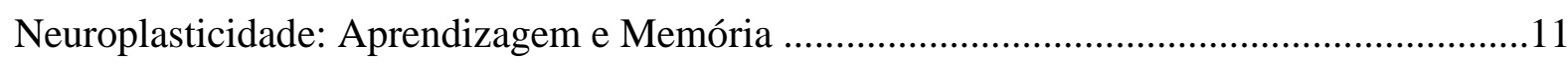

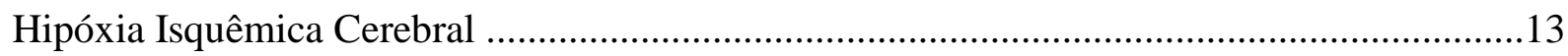

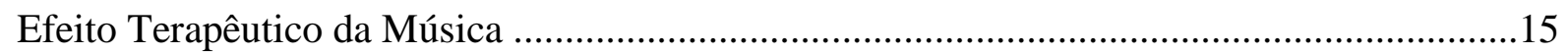

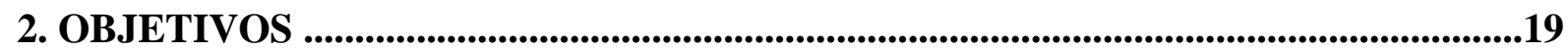

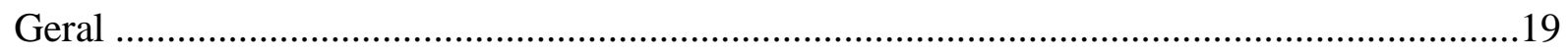

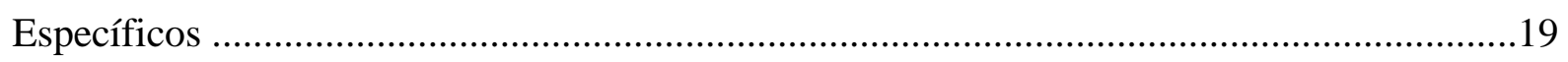

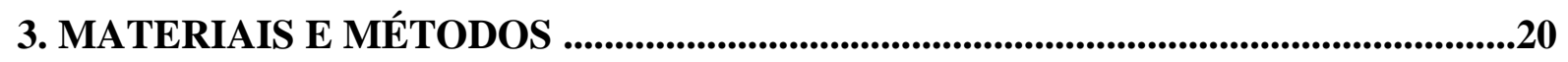

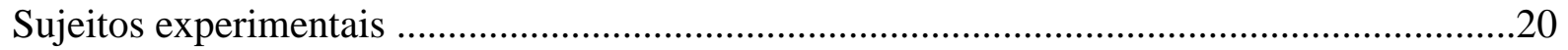

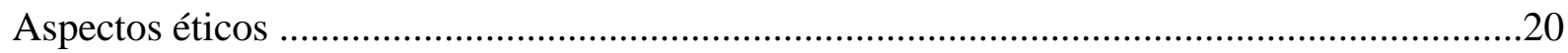

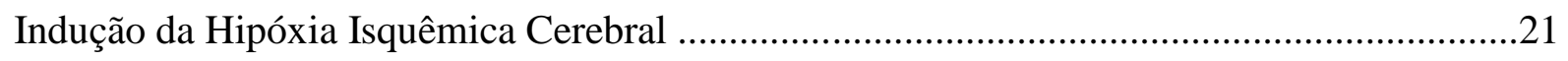

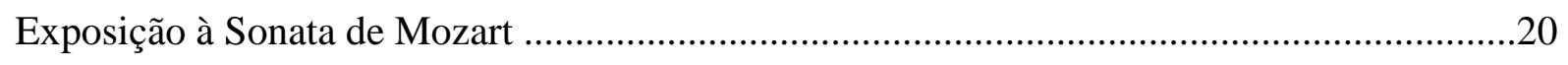

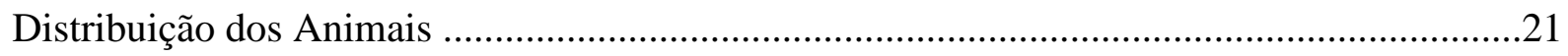

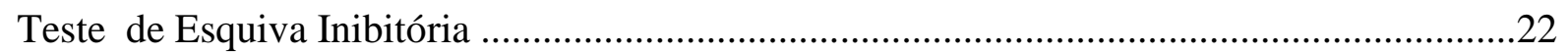

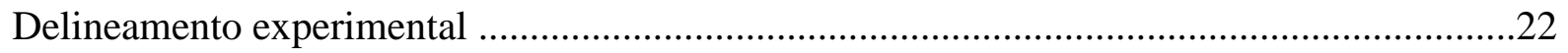

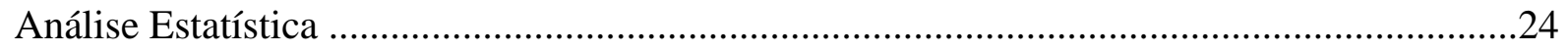

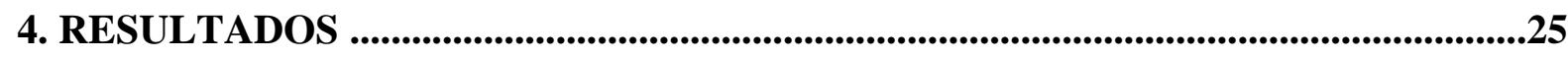

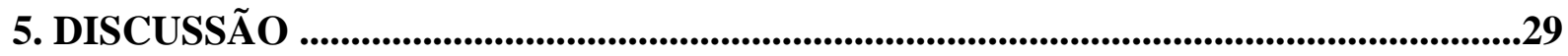

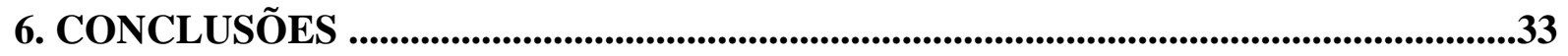

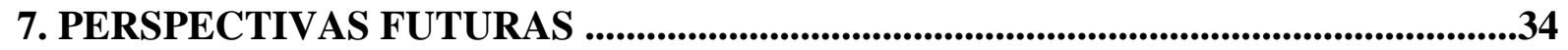

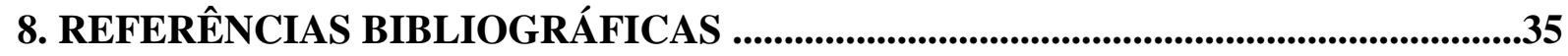

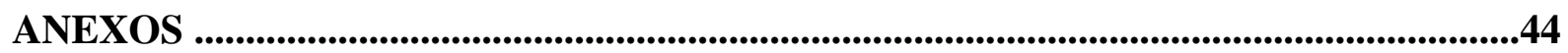




\section{INTRODUÇÃO}

\section{Neuroplasticidade: Aprendizagem e Memória}

A aprendizagem se caracteriza por mudanças relativamente duradouras de comportamentos adquiridas por experiência, observação ou prática. A memória, por sua vez, pode ser definida como registros de representações de informações adquiridas por meio de experiências. Desta forma, aprendizagem e memória estão intimamente relacionadas, pois um indivíduo apresenta capacidade de adaptação e modificação do comportamento quando exposto a novas experiências (Eichenbaum, 2004; Izquierdo et al., 1998).

Existem diferentes tipos de memória que podem ser resumidamente classificadas de acordo com o tempo de duração da retenção, em memória operacional (memória imediata que dura segundos ou poucos minutos), memória de curta duração - MCD, (que se desenvolve em alguns segundos ou minutos e dura várias horas) e memória de longa duração - MLD, (que consolida lentamente e é relativamente estável), ou ainda quanto à natureza da MLD, declarativa ou não-declarativa (Cassilhas, Tufik \& de Mello, 2016; Emptage \& Carew, 1993; Izquierdo et al., 1999). E, apesar do constante recebimento de informações por meio dos sentidos, apenas alguns fragmentos são retidos de forma duradoura. A intensidade e a duração dessas memórias são determinadas pela importância da informação, grau de atenção e a emoção envolvida no momento da aquisição (Izquierdo et al., 1998).

Ao longo das décadas, o conhecimento sobre a base neuronal e molecular de memória tem avançado muito, no entanto, atualmente, sabe-se que os tipos de memórias são identificados como mecanismos separados. Mamíferos têm uma capacidade excepcional para se adaptar aos ambientes usando modificações de comportamento resultantes de aprendizados e experiências passadas, devido ao desenvolvimento do neocórtex. As habilidades de aprendizagem e memória tornaram-se vitais ao longo da evolução das espécies (Cassilhas, Tufik \& de Mello, 2016). Estas habilidades desencadeiam modificações sinápticas nas redes neurais, através de uma interação de múltiplas vias moleculares aferentes, e também por meio da percepção das experiências (Cammarota et al., 2005; Sun et al., 2001).

Entretanto, para que ocorram os processos de aprendizagem e memória, há necessidade do envolvimento de diversas estruturas cerebrais, como hipocampo, amígdala, 
córtex entorrinal e córtex pré-frontal, as quais formam, juntamente com outras estruturas, o circuito dos processos emocionais, o sistema límbico, que se conectam para gerar diversos comportamentos (Chan, 2009). Mas, embora as MCD e MLD possam compartilhar dos mesmos estímulos de entrada e emitirem respostas aprendidas equivalentes, não configuram etapas sequenciais de um único fenômeno. Isso implica esclarecer que tratamentos podem inibir a MCD, deixando a MLD intacta para a mesma tarefa no mesmo animal, pois são adquiridos em vias moleculares independentes. A diferença mais notável entre os dois tipos de memória é que a MLD requer uma síntese de proteínas no hipocampo, e áreas adjacentes, ao passo que a MCD não há esta necessidade (Cammarota et al., 2005; Izquierdo et al., 2004).

As MLD não são estabelecidas de forma definitiva, exige uma série de alterações funcionais, pois a consolidação requer um número de moléculas precisamente cronometradas nos neurônios que atuam nesta função. Estes processos são sequencialmente ligados de forma complexa, e tem sido melhor estudados na região CA1 da hipocampo, que está envolvido em muitas, senão todas as formas de memória explícita em mamíferos (Izquierdo e McGaugh, 2000).

Acreditava-se até os últimos anos, que o sistema nervoso central (SNC) dos mamíferos atingia a completa maturação logo após o nascimento e que apenas algumas modificações poderiam ocorrer ao longo da vida. Este paradigma, entretanto, começou a mudar. Atualmente, sabe-se que ele apresenta plasticidade persistente ao longo de todas as fases da vida, o cérebro humano está constantemente sujeito a alterações plásticas (Leuner \& Gould, 2010). Plasticidade é um conceito bastante amplo, mas que pode ser compreendido como um fenômeno no qual o sistema nervoso é capaz de modificar-se funcionalmente em decorrência de experiências anteriores. Estas adaptações promovem alterações sinápticas e podem aumentar ou diminuir a transmissão de impulsos, com a consequente modulação do comportamento, que explicam a capacidade dos neurônios de mudar suas respostas em resposta a determinados estímulos (Mcmahon \& Barrionuevo, 2002).

A neuroplasticidade pode possibilitar a geração de circuitos neuronais em diversas regiões encefálicas, estruturas envolvidas com aprendizagem e memória, como hipocampo e adjacências, podem ser reorganizadas para que funções cognitivas prejudicadas passem a envolver circuitos completamente novos com elementos que anteriormente não eram utilizados, assim como a modulação de antigas conexões para a manutenção ou prevenção de total perda do seu funcionamento. A plasticidade neuronal permite o SNC aprender novas 
habilidades, consolidar e recuperar memórias, reorganizar redes neuronais em resposta a estímulos ambientais e recuperação após lesões (de los Angeles et al., 2016; Hallet, 2001; Knaepen et al., 2010; Schlett, 2006).

O cérebro é altamente sensível às lesões e, em especial, em partes cruciais ao funcionamento cognitivo. A hipóxia isquêmica cerebral (HI), por exemplo, é um fator que predispõe a incidência de infarto cerebral que representa a terceira principal causa da morte e uma das principais causas de incapacidade a longo prazo (Girard et al., 2014; Mohr, Caplan \& Melski, 1978). Este evento pode ocasionar comprometimentos cognitivos como déficits no processamento auditivo, de linguagem, aprendizagem e memória, alterações atencionais, de planejamento e tomada de decisão (du Plessis \& Volpe, 2002; Smith et al., 2014).

Danos mais comuns em casos de lesões cerebrais são percebidos nos processos de aprendizagem e memória em decorrência da diminuição significativa no volume do hipocampo e atrofias em regiões adjacentes (Ortega et al., 2004). Os circuitos do hipocampo, áreas CA1, CA2 e CA3, desempenham um papel importante nos aspectos de memória. Devido à vulnerabilidade à hipóxia, os neurônios no hipocampo podem ser afetados no estágio muito inicial da isquemia cerebral (Newrzella et al., 2007).

\section{Hipóxia Isquêmica Cerebral}

O funcionamento das células nervosas depende do fornecimento adequado de oxigênio e glicose, por meio do fluxo sanguíneo. Assim, a manutenção em nível apropriado desses suprimentos é necessária para a produção regular de energia, e garantia da integridade do funcionamento cerebral (Gill \& Perez-Polo, 2008). As células nervosas utilizam aproximadamente $20 \%$ do oxigênio consumido no organismo, porém representam apenas $2 \%$ do peso corporal, o que demonstra sua alta atividade oxidativa (Li et al., 2002). O SNC possui mecanismos próprios de autorregulação da circulação sanguínea, independente de variações do fluxo, mas, em situação de lesão cerebral, esse mecanismo encontra-se prejudicado na região acometida, ocorrendo alterações no nível desses suprimentos, e déficits comportamentais e cognitivos podem ser manifestados, o que demonstra a vulnerabilidade do encéfalo a insultos (Shalak \& Perlman, 2004; Zhang et al., 2006).

O dano cerebral por HI surge de eventos moleculares interligados de forma tempo- 
dependente, desde redução energética, excitotoxicidade, disfunção mitocondrial e estresse oxidativo. A parada da circulação cerebral pode cessar em 20 segundos o metabolismo aeróbico, e em 5 minutos pode provocar a anóxia, oferta de oxigênio abaixo do nível crítico, interferindo no funcionamento das mitocôndrias, bloqueando a fosforilação oxidativa, diminuindo níveis de Adenosina Trifosfato (ATP) e glicose. A atividade neuronal cessa e, se a oferta de oxigênio não for rapidamente restaurada, a célula morre (Baky et al., 2010; Bari, Dalley \& Robbins, 2008; McLean \& Ferriero, 2004).

A falta de ATP faz com que as bombas iônicas dependentes de energia $\left(\mathrm{Na}^{+} / \mathrm{K}^{+}\right)$não consigam exercer suas funções e impossibilite que os neurônios desencadeiem os potenciais de ação de despolarização da membrana, com entrada de sódio $\left(\mathrm{Na}^{+}\right)$e água na célula, causando edema citotóxico e morte celular por necrose, completa desintegração celular. Com a falha na bomba de $\mathrm{Na}+\mathrm{K}+$, ocorre acúmulo de cálcio $\left(\mathrm{Ca}^{2+}\right)$, que resulta em disfunção mitocondrial e falência energética, culminando na morte neuronal por apoptose, um tipo de morte celular por meio da qual uma célula se autodestrói, decorrente de uma sequência de eventos dependentes de energia (McAuliffe, 2009; Pagnussat et al., 2007). Uma vez que os potenciais de ação ficam impossibilitados de serem desencadeados, há, simultaneamente, uma desestabilização na liberação dos neurotransmissores, acarretando excesso ou falta dos mesmos na fenda sináptica. Os neurotransmissores são substâncias químicas produzidas por células neuronais e responsáveis pelo envio de informações a outros neurônios, constituindo o meio de comunicação entre eles (Erecinska \& Silver, 2001; Perlman, 2004).

Os déficits neuronais permanentes são as complicações mais temidas da HI. Em geral, ocorre como uma lesão cerebral global, mais conhecida como encefalopatia hipóxica isquêmica, que anatomicamente se manifesta com dano tecidual, com consequente perda de porções do córtex, tronco encefálico, gânglios basais e hipocampo, refletindo a suscetibilidade da matéria cinzenta à excitotoxicidade (Fields, 2010; Girard et al., 2014; Kent et al, 2012). Alguns dos efeitos mais graves da hipóxia encontram-se no hipocampo. Durante a HI, a atividade elétrica cessa nessa área, porém, o disparo neuronal é uma característica acentuada em uma das suas regiões, a CA1, e se torna mais vulnerável em segundos de HI. Nas áreas como CA3, CA4 do hipocampo e, ainda, no tálamo e corpo estriado, a HI crônica tem demonstrado morte neuronal. Uma vez que o hipocampo é uma estrutura fundamental para a as funções de aprendizagem e memória, a perda de células nesta estrutura, faz com que tais funções sejam significamente prejudicadas (Kim et al., 2011; Zaidi, 2010). 
Os prejuízos são variáveis ao indivíduo, iniciado desde o insulto e se estendendo até o período de recuperação. Com isso, a severidade e a distribuição das lesões neurológicas originárias da HI dependem de fatores como: duração do dano, fase de desenvolvimento do indivíduo e região lesionada (Martinez-Biarge et al, 2011). É válido destacar o período de desenvolvimento do SNC, pois encéfalos imaturos são altamente suscetíveis às lesões quando comparados aos adultos, devido à importância do suprimento sanguíneo ao desenvolvimento. Sabe-se que o cérebro imaturo é bastante vulnerável ao dano oxidativo devido as suas limitadas capacidades antioxidantes (Kumral et al., 2004; Mclean e Ferriero, 2004). Entre os efeitos prejudiciais da HI, é muito provável que ocorram deficiências motoras e cognitivas de longo prazo, como paralisia cerebral, epilepsia, distúrbios de aprendizagem e comportamentais, e ainda com possibilidades terapêuticas limitadas (Carloni et al., 2007).

Um modelo experimental usado para simular a HI humano é a administração de nitrito de sódio $(\mathrm{NaNO} 2)$. A significativa diminuição da concentração de hemoglobina e formação de meta-hemoglobina após o tratamento de NaNO2 é o mais reconhecível sinal de toxicidade e danos neuronais (Jyoti et al., 2003; Gladwin, Crawford \& Patel, 2004). A hemoglobina tem como principal função o transporte de oxigênio $(\mathrm{O} 2)$ no sangue, e a metemoglobina é uma hemoglobina anormal, incapaz de executar sua função (Ger et al., 1996).

Estudos como o de Zaidi (2010), demonstram degeneração em regiões do hipocampo, CA1 a CA4 e giro dentado, após indução de HI por NaNO2. A degeneração foi observada por meio de núcleos picnóticos nas células nervosas e densidade celular expressivamente menor nestas regiões. A HI diminuiu significativamente a concentração de hemoglobina e provocou alterações metabólicas da hemoglobina, e produção da metemoglobina (Baky et al., 2010).

\section{Efeito Terapêutico da Música}

O uso da música como método de promoção de saúde tem sido frequentemente relatado na literatura. As emoções eliciadas pela música se originam a partir de um nível mais profundo de comunicação do que as associações aprendidas superficialmente, o que implica haver conotações emocionais universais, ligadas a componentes inatos envolvidos na percepção emocional de estruturas harmônicas (Bakker \& Martin, 2015; Krumhansl, 1997).

A música influencia o funcionamento fisiológico em curto prazo, desencadeando 
respostas no tronco cerebral e nos sistemas neuroquímicos, que diminuem a excitação simpática e aumentam a atividade parassimpática. São afetados ainda os mesmos sistemas neuroquímicos que mediam à sensação de prazer, especialmente o dopaminérgico, associando a música ao mecanismo de recompensa, assim como outros estímulos, alimentos, drogas e sexo. O som ritmado e harmônico parece aliviar sintomas emocionais e físicos, mostrando efetividade no manejo da dor, ansiedade e estresse, agindo em princípios hemodinâmicos, como frequência cardíaca, pressão arterial, temperatura corporal, além regularizar o ritmo respiratório, o sono e o relaxamento muscular (Chanda \& Levitin, 2013; Lin et al., 2013).

Tem sido muito estimado o uso da música como instrumento de estimulação para melhoria no desempenho de habilidades cognitivas e comportamentais (Chengzhi et al., 2011; Kraus et al., 2014; Xing et al., 2016). As ativações devem-se ao fato de que a música provoca estimulação de circuitos neurais ligados ao comportamento e emoções, em regiões como hipocampo e córtex pré-frontal (Hatem, Lira \& Mattos, 2006; Verrusio et al., 2015). As melhorias que a música tem manifestado sobre a cognição incluem a memória, processos atencionais, funções gerais de inteligência, funções executivas e processamento da linguagem, envolvendo as funções cognitivas de maneira positiva, reforçando o potencial da neuroplasticidade, que vai além de simples estímulos auditivos ambientais. Entretanto os mecanismos neuroplásticos envolvidos ainda permanecem pouco esclarecidos (Kraus et al., 2014; Zhu et al., 2014).

Estudos também apontam que programas de formação musical têm um impacto biológico sobre o SNC em desenvolvimento. Os resultados relatam diferenças comportamentais e neurofisiológicas entre músicos e não músicos, o que parece estar predominantemente atribuído a plasticidade relacionada à formação musical. Uma vez que o sistema nervoso tem significante potencial de reorganização funcional, parece que o treinamento auditivo é capaz de provocar mudanças estruturais e funcionais nas redes neurais (Heim et al., 2013; Zatorre \& Salimpoor, 2013).

Desta forma, tem sido reconhecido que efeitos de um ambiente enriquecido, com estímulos sonoros, visuais e/ou sensitivos proporcionam melhores avanços em termos de readaptação funcional no tratamento de lesões neurológicas em comparação a pacientes que não vivenciam tais ambientes (Fukui \& Toyoshima, 2008). Todavia, é válido diferenciar estímulos sonoros musicais de ruídos. O estudo de Liu et al. (2015) demonstrou que os ratos expostos a um ruído de nível elevado (123 dB SPL), apresentaram aprendizagem mais lenta, 
especialmente em tarefas de memória espacial. Assim como em outros estudos em que ratos expostos a ruídos, de intensidade moderada, apresentaram prejuízos cognitivos, possivelmente devido ao aumento do estresse oxidativo, causando degeneração neuronal em muitos núcleos auditivos e em regiões cerebrais importantes à cognição, como a região hipocampal, estriatal e frontal (Cheng et al., 2011; Chengzhi et al., 2011; Cui, Wer \& She, 2009).

Com isso, um ambiente enriquecido pode melhorar a codificação da memória e sua posterior recordação (Kroneisen \& Erdfelder, 2011; Nairne \& Pandeirada, 2008). Entretanto, isso parece não ser aplicável a qualquer contexto auditivo, o que quer dizer que sons ambientais não melhoram o desempenho da memória, pois este efeito está relacionado com características intrínsecas da música, ao invés de uma estimulação auditiva geral (Ferreri, Bigand \& Bugaiska, 2015). Evidências experimentais indicam que a exposição de ratos à música é capaz de modular o desenvolvimento do cérebro e mecanismos da plasticidade cerebral, com aumento na neurogênese hipocampal (Amagdei et al., 2010; Strait et al., 2014).

A melhoria na aprendizagem espacial-temporal de curto prazo como manifestação do chamado efeito Mozart (EM) foi o início de uma nova perspectiva da musicoterapia. Inicialmente foi testado por Rauscher et al. (1993), que mostraram melhorias dos participantes na capacidade de raciocínio espaço-temporal em tarefas específicas do teste de inteligência Stanford-Binet, em um curto período de tempo, após ouvirem uma das Sonatas de Mozart para dois pianos (K.448). Em 1995 Rauscher et al. replicaram o estudo com estudantes universitários, e sugeriram que os padrões de coerência no eletroencefalograma (EEG) foram significantes para indicar que ouvir música melhora a organização de padrões de disparo corticais necessários para o raciocínio espaço-temporal.

Em seguida o EM foi usado para se referir a qualquer melhoria cognitiva associada ao ouvir a música de Mozart. Além disso, o aumento da atividade fisiológica nas áreas frontais e temporais esquerdas do cérebro também foi observado em resposta à escuta da Sonata de Mozart (Hughes et al., 1998; Rideout \& Laubach, 1996). Uma das hipóteses levantadas sobre o EM foi a especificidade do estímulo, que sugere que o processamento cognitivo realizado pelo ouvinte à Sonata de Mozart permanece mais ou menos constante. E essa constância do padrão das notas musicais, manteria a complexidade do estímulo auditivo e ativaria as funções cognitivas do ouvinte, uma suposição que poderia explicar por que Mozart, ao invés de outros compositores (Marsden, 1987; Kliewer, 1999). Embora, ainda sejam discutidas as características necessárias da música a fim de manifestar o EM, tal efeito caracteriza um 
fenômeno sociocultural e científico de enorme magnitude, que continua sendo pesquisado até os dias de hoje (Beauvais, 2015).

Outros estudos foram desenvolvidos com o objetivo de tentar compreender mecanismos despertados por esse efeito e explorar consequências a longo prazo da exposição à Sonata de Mozart sobre as habilidades cognitivas, visto que tem mostrado efeito modulatório na atividade cerebral. Estudos relatam, ainda, que este estímulo musical é capaz de diminuir descargas da atividade elétrica cerebral de pacientes epilépticos, como também aumentar ondas cerebrais em regiões relacionadas à cognição em adultos e idosos saudáveis, no eletrencefalograma(EEG). Diferentemente de estudos que exploraram as mesmas respostas a outros compositores, como Beethoven (Coppola et al., 2015; Perlovsky et al., 2013; Verrusio et al., 2015).

Além disso, a Sonata de Mozart (K 448) tem sido utilizada para tratar déficit de atenção, epilepsia, depressão, ansiedade, estresse e demência, refletindo em reorganizações corticais funcionais (Kim et al, 2006; Lagasse, 2014; Lin \& Yang, 2015; Xing et al., 2016). Tem também demonstrando melhorias comportamentais e cognitivas, na atenção, concentração, aprendizagem e memória, como também tem proporcionado alterações no estado de humor, com aumento do sentimento de alegria e diminuição da tristeza, e sensação de relaxamento (Dewi, Rusmawati \& Ratnaningsih, 2015; Hausmann, Hodgetts \& Eerola, 2016).

Contudo, o provável efeito da música clássica como método terapêutico, facilitador de processos psicológicos, e como estímulo à neuroplasticidade, faz com que a Sonata de Mozart passe a ser reconhecida não como um simples elemento perceptivo, mas também uma rica estratégia terapêutica, a fim de promover a readaptação funcional de áreas lesionadas do SNC (Sarkamo et al., 2013; Strait et al., 2014; Zhu et al., 2008).

Diante desse contexto, observa-se que todas estas melhorias relatadas como efeito à exposição da Sonata de Mozart para dois pianos (K.448) são significativas e suficientemente interessantes para a finalidade deste estudo. Considera-se também a necessidade de revelar novas possibilidades de técnicas de estimulação e reabilitação das funções cognitivas, a fim de que menos indivíduos sejam acometidos com grandes prejuízos nessas funções, além da curiosidade em investigar se esses efeitos são dependentes da idade do sujeito investigado. 


\section{OBJETIVOS}

\section{Geral}

Avaliar a eficácia da Sonata de Mozart para dois Pianos (K. 448) na aprendizagem e memória de ratos expostos à hipóxia cerebral.

\section{Específicos}

- Observar o desempenho comportamental de ratos no teste de esquiva inibitória, ao longo do desenvolvimento (1 a 4 meses).

- Avaliar a interferência da exposição aguda e crônica da Sonata de Mozart (K.448) no desempenho comportamental no teste de esquiva inibitória de ratos em diferentes fases de desenvolvimento.

- Identificar as possíveis alterações na aprendizagem e memória de ratos em condição experimental de hipóxia isquêmica cerebral.

- Analisar a eficácia da exposição aguda e crônica da Sonata de Mozart (K.448) nos danos à aprendizagem e memória decorrentes da hipóxia isquêmica cerebral. 


\section{MÉTODO}

\section{Sujeitos Experimentais}

Para a realização dos testes experimentais foram recrutados ratos Rattus norvegicus (Wistar), fêmeas $(n=48)$, de 1 mês de idade que foram testados até os 4 meses. Todas foram provenientes do Biotério da Faculdade de Medicina da UNB, com uma média de \pm 60 g, que chegaram ao Laboratório de Patologia/Faculdade de Medicina pronto para a realização dos testes experimentais, resguardando o período de habituação à área. Os animais ficaram alojados em grupos de quatro ratos por caixa (gaiolas de polipropileno 41 x 34 x $16 \mathrm{~cm}$ ), mantidos em ciclos claro/escuro de 12 horas, e alimentados com ração ad libitum e água diariamente, exceto no período das sessões de teste e exposição à música (período entre 8:0010:00 e 16:00-18:00 horas).

\section{Aspectos Éticos}

Todos os procedimentos experimentais deste estudo foram aprovados pelo Comitê de Ética no Uso Animal (CEUA) do Instituto de Ciências Biológicas da Universidade de Brasília, aprovado pelo Pareceres n ${ }^{\circ} 80243 / 2013$ e no 67736/2014, em anexo.

\section{Indução da Hipóxia Isquêmica cerebral}

A indução da hipóxia foi realizada com nitrito de sódio (NaNO2), em administração de $60 \mathrm{mg} / \mathrm{kg}$ por via subcutânea, aos 3 meses, durante 15 dias consecutivos, conforme protocolo adaptado da literatura científica na área (Baky et al., 2010).

\section{Exposição à Sonata de Mozart}

Uma sala foi padronizada para tocar a Sonata de Mozart para dois Pianos (K. 448), em intensidade uniformizada do som com decibelímetro em nível sonoro médio de $65 \mathrm{~dB}$. $\mathrm{O}$ aparelho de som era mantido em uma posição, de tal forma que todas as caixas ficavam a uma mesma distância (aproximadamente $50 \mathrm{~cm}$ de distância, conforme demonstrado na Figura 1), a fim de garantir a mesma intensidade de som para todos os sujeitos experimentais. A Sonata foi escrita em três movimentos: Allegro con spirito; Andante e Molto Allegro e apresentada na tonalidade de Ré Maior.

O arquivo da Sonata de Mozart para dois pianos (K. 448) esteve no formato MP3. A 
duração do arquivo original que era de 22 minutos e 3 segundos, mas foi adaptado para ter duração de 2 horas, o que necessitou ser repetido 5 vezes e meia, no mesmo arquivo. $\mathrm{O}$ arquivo foi salvo em um Pen Drive inserido em um aparelho emissor de som com entrada USB. A música era tocada por $4 \mathrm{~h}$ alternadas, $2 \mathrm{~h}$ no período da manhã e $2 \mathrm{~h}$ no período da tarde, separada em movimentos (Tasset et al., 2012). O tratamento musical foi realizado nos animais com 1 mês e repetidos ao completarem 2, 3 e 4 meses, durante 4 dias consecutivos antes de completarem cada idade (tratamento agudo) ou diariamente durante 4 meses (tratamento crônico). Os testes experimentais foram realizados quando os animais completavam cada idade. Os animais controles do estudo não receberam a musicoterapia.

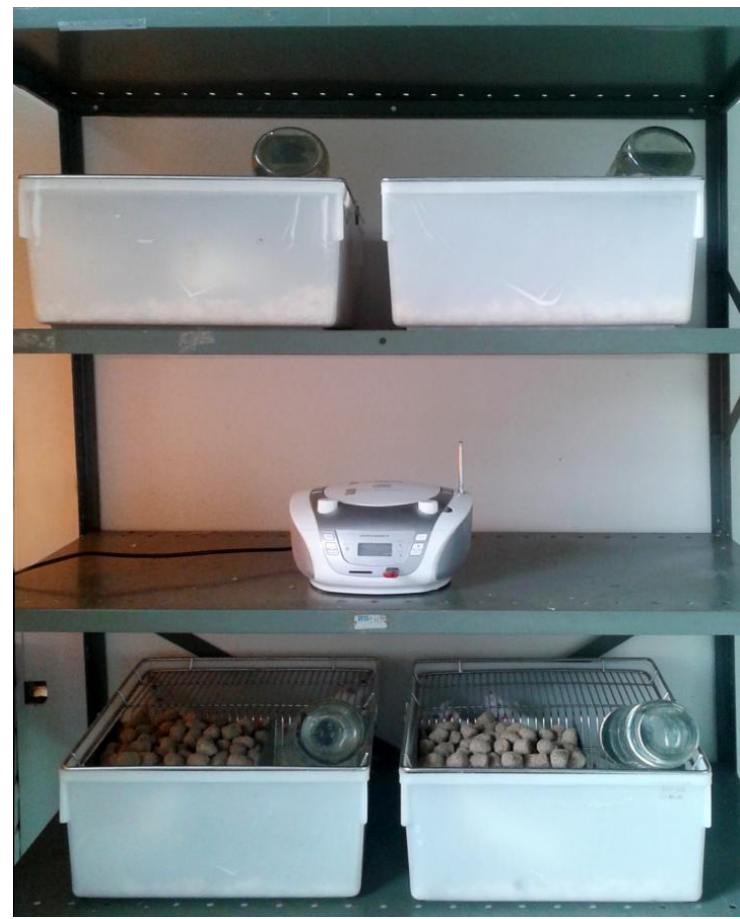

Figura 1: Disposição do aparelho de som e caixas dos animais que receberiam a Sonata de Mozart.

\section{Distribuição dos Animais}

Os animais foram distribuídos aleatoriamente em grupos (n=8/grupo) totalizando 48 animais, organizados da seguinte forma:

$\mathrm{G} 1=$ controle

G2 = controle (hipóxia aos 3 meses)

G3 = música aguda (4h/dia, 4 dias antes de atingir cada idade)

G4 = música aguda (hipóxia aos 3 meses)

G5 = música crônica (4h/dia, durante 4 meses)

G6 = música crônica (hipóxia aos 3 meses) 


\section{Teste de Esquiva Inibitória - "step-down"}

Foi utilizado o teste de esquiva inibitória (step-down) para avaliação das memórias (curta e longa duração) e aprendizagem. Os parâmetros de avaliação envolveram uma fase de treino e pós-treino e um choque de baixa intensidade $(0,4 \mathrm{~mA}$, por $1 \mathrm{seg})$ que serviu de estímulo aversivo para que o animal deixasse de executar uma determinada tarefa que foi a ele apresentada. $\mathrm{O}$ animal deveria associar o contexto do aparato, inicialmente não aversivo, ao recebimento de choque. Esse procedimento foi utilizado como mecanismo de retenção da memória (Izquierdo et al., 1998).

O aparelho de esquiva inibitória (EP-104 INSIGHT) foi composto de uma caixa de metal $(50 \times 25 \times 25 \mathrm{~cm})$ com uma plataforma de $(5 \times 8 \times 25 \mathrm{~cm})$ e uma parede frontal de vidro. A parte interna possuia barras de alumínio paralelas com distância de $1 \mathrm{~cm}$. O aparato era conectado a um painel de controle que possibilitava disparar choque elétrico previamente determinado (Figura 2).

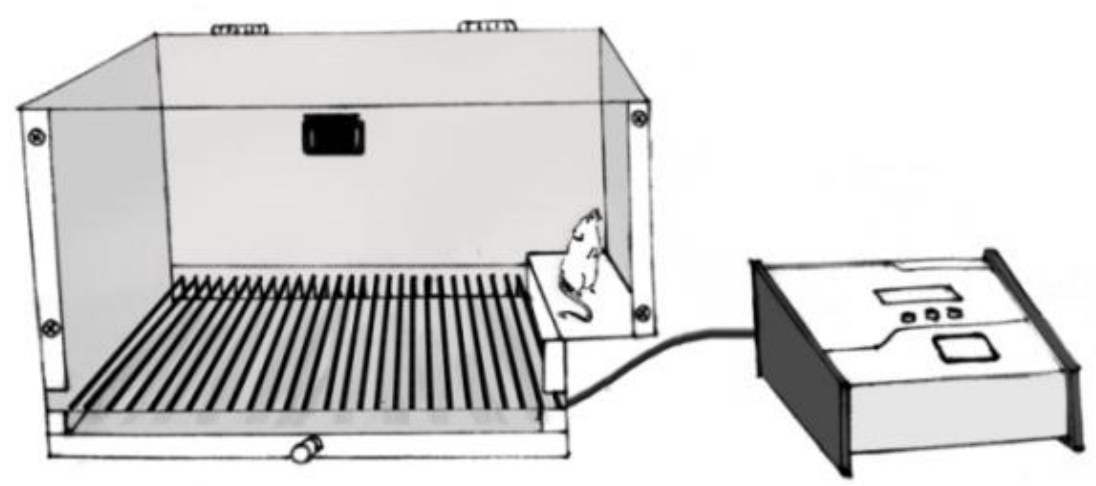

Figura 2: Aparelho utilizado no teste de esquiva inibitória do tipo step-down, munido da caixa e seus sensores.

\section{Delineamento Experimental}

A avaliação experimental na etapa considerada aguda foi investigada em três dias e repetida a cada mudança de idade dos ratos. A etapa de habituação foi realizada somente na primeira vez em que os animais foram avaliados, conforme demonstrado no desenho experimental (Figura 3). No $1^{\circ}$ dia (sessão de Habituação), os animais foram inseridos na plataforma da caixa de esquiva inibitória, individualmente, por 180 segundos (latência máxima), para habituação ao ambiente do teste. Padronizou-se a realização dos testes no período da manhã ( 8 às 12h) para a realização dos treinos e testes, para que não ocorressem interferências do ciclo circadiano dos animais. Após a observação de cada animal, os aparatos foram limpos com álcool 10\% a fim de minimizar o estímulo olfativo e evitar interferências no comportamento dos ratos. No $2^{\circ}$ dia (Sessão de Treino) cada animal foi colocado, 
cuidadosamente, na mesma plataforma com a face virada para o lado oposto ao observador. Assim que o animal desceu da plataforma e colocou as quatro patas nas barras, recebeu um choque de $0,4 \mathrm{~mA} / \mathrm{seg}$, e fora retirado imediatamente da caixa. A aprendizagem, com refleto para a MCD foi testada $1 \mathrm{~h}$ após o treino.

No $3^{\circ}$ dia, após $24 \mathrm{~h}$ do teste de MCD, foi realizado o teste da MLD, seguindo os mesmos critérios procedimentais. Mediu-se o tempo que cada animal levou para descer da plataforma (latência de descida) novamente como uma medida de retenção de aprendizagem e memória. Normalmente a reexposição ao ambiente aversivo produz aumento da permanência na plataforma, indicando que o estímulo é suficientemente forte para produzir alteração na memória dos animais. Ou seja, quanto mais tempo o animal permanecer na plataforma, maior será a latência de descida, indicando que ocorreu aprendizagem na relação entre o contexto e ocorrência do choque (Deacon, 2002).

(A)
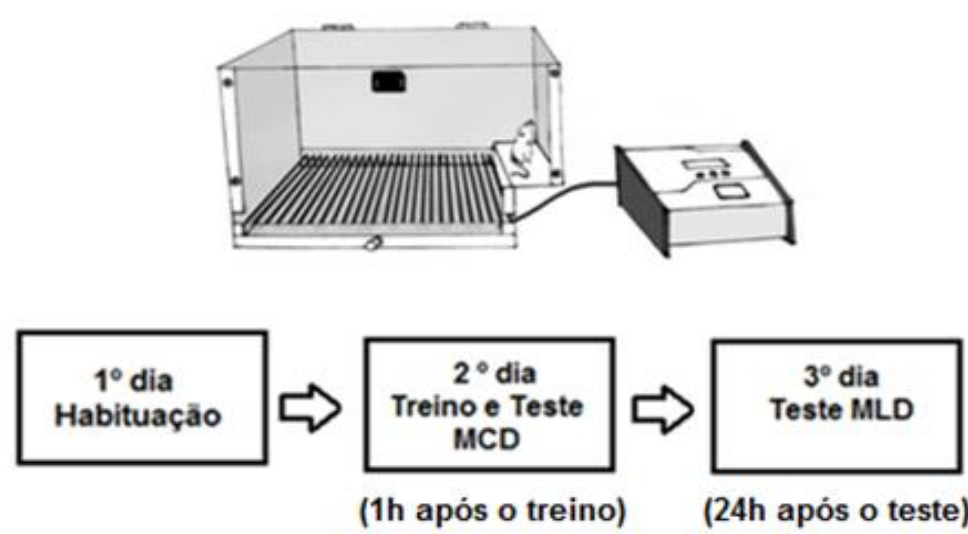

(B)
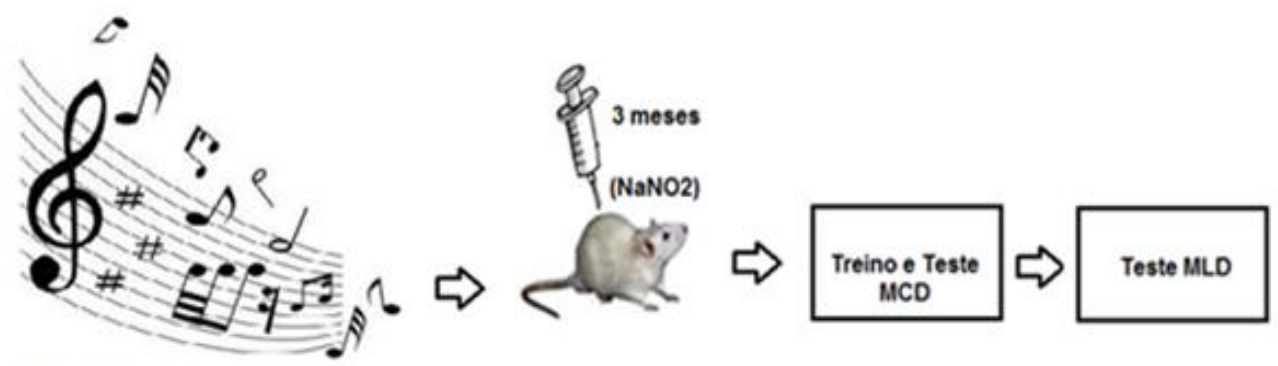

4h/dia - 4 dias consecutivos

antes de completarem 1,2,3 e 4 meses

(continua) 
(C)

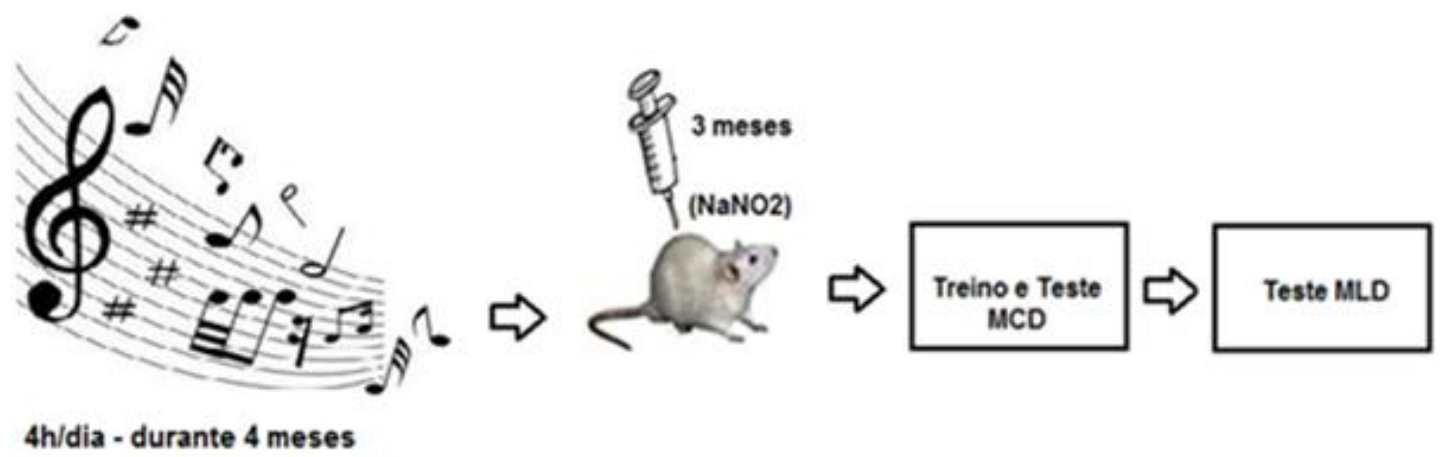

Figura 3: Avaliação da aprendizagem/MCD e MLD de ratos avaliados no teste da esquiva inibitória. A Quando avaliados pela primeira vez, todos os animais passaram por 3 etapas de teste: habituação, treino (choque) e testes (MCD e MLD). B - exposição à Sonata de Mozart (K.448) de modo agudo: ratos com 1, 2, 3 e 4 meses, sendo a música tocada durante 4 dias antes de completarem cada idade. Um grupo complementar subdividido em animais controles e música aguda foi induzido experimentalmente à hipóxia isquêmica aos 3 meses de idade e avaliados novamente aos 4 meses de idade. C - exposição à Sonata de Mozart (K.448) de modo crônico: ratos com 1, 2, 3 e 4 meses, sendo a música tocada diariamente durante 4 meses. Um grupo complementar subdividido em animais controles e música crônica foi induzido experimentalmente a hipóxia isquêmica aos 3 meses de idade e avaliados novamente aos 4 meses de idade. $\mathrm{MCD}=$ memória de curta duração, $\mathrm{MLD}=$ memória de longa duração.

\section{Análise Estatística}

Foram coletadas medidas que visavam mensurar informações relativas à aprendizagem/MCD e MLD. As análises estatísticas dos resultados foram realizadas por meio da Análise de Variância (ANOVA) de uma via com medidas repetidas. As diferenças significativas, comparadas pelo teste post-hoc de Newman Keuls, foram verificadas dentre os grupos de diferentes idades em comparação aos seus respectivos grupos controles. A probabilidade indicativa da existência de diferença estatisticamente significante foi de $p \leq 0,05$. Os dados foram analisados utilizando o software estatístico GraphPad Prism, versão 5.01@, 2010 (San Diego, CA). 
Considerando os ratos controles investigados em diferentes fases de desenvolvimento, se observou diferença estatística somente durante o treino aos 4 meses, quando a avaliação foi feita em comparação quando eles estavam com 1 mês de idade: treino $\left[\mathrm{F}_{(3,31)}=3,578\right.$; $\mathrm{p}=0,0311] ; \operatorname{MCD}\left[\mathrm{F}_{(3,31)}=2.711 ; \mathrm{p}=0,0709\right]$ e $\operatorname{MLD}\left[\mathrm{F}_{(3,31)}=2,072 ; \mathrm{p}=0,1346\right]$. Entretanto, quando a comparação foi feita intragrupos observou-se aprendizagem refletida na MCD aos 3 $\left[\mathrm{F}_{(2,23)}=53,61 ; \mathrm{p}<0,001\right]$ e 4 meses de idade $\left[\mathrm{F}_{(2,23)}=5,416 ; \mathrm{p}=0,0127\right]$. Ainda nas avaliações intragrupos observou-se diferença estatística na MLD, quando comparados aos resultados representativos das fases de treino e MCD. Esses resultados serviram de controles para os experimentos de exposição a música de forma aguda e crônica (Figura 4).

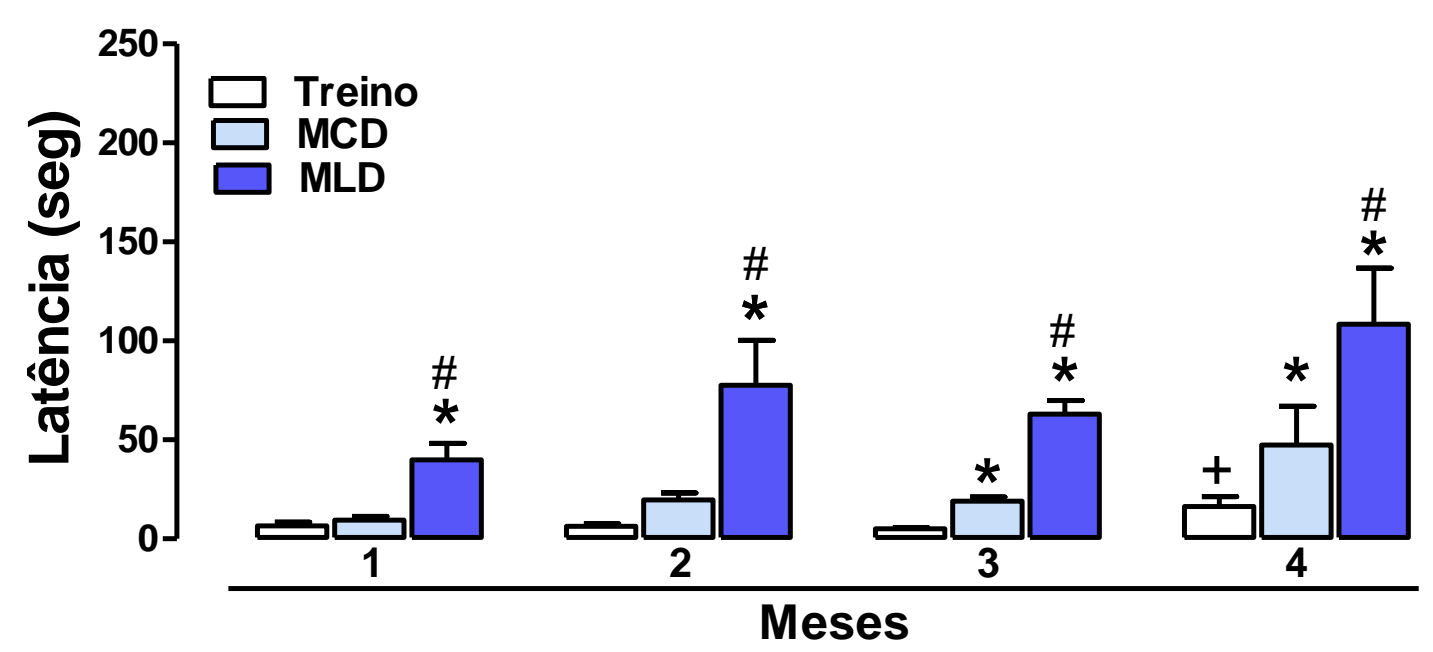

Figura 4 - Avaliação da aprendizagem/MCD e MLD de ratos controles no teste da esquiva inibitória nas idades de 1, 2, 3 ou 4 meses (grupo - G1). As avaliações em diferentes idades sempre eram repetidas com os mesmos animais. $+p<0,05$ representa diferença estatística em relação aos treinos dos ratos com 1 mês de idade; * $p<0,05$ representa diferença estatística em relação ao treino de cada idade; $\# p<0,05$ representa diferença estatística em relação aos dados representativos da MCD (ANOVA, Teste de Newman Keuls). MCD= Memória de curta duração; MLD= Memória de longa duração.

Outro grupo experimental, exposto à Sonata de Mozart para dois Pianos durante 4h/dia, em um período de 4 dias na mudança de cada idade, observou-se que durante o treino o efeito da música foi evidenciado aos 3 e 4 meses de idade $\left[\mathrm{F}_{(3,31)}=5,059 ; \mathrm{p}=0,0086\right]$, enquanto o aprendizagem/MCD $\left[\mathrm{F}_{(3,31)}=4,376 ; \mathrm{p}=0,0153\right]$ e $\operatorname{MLD}\left[\mathrm{F}_{(3,31)}=3,651 ; \mathrm{p}=0,0291\right]$ foram evidenciados significativamente desde os 2 meses de idade (Figura 5). Na avaliação intragrupos, o efeito mais pronunciado foi observado aos 2 meses de idade $\left[\mathrm{F}_{(2,23)}=8,359\right.$; $\mathrm{p}=0,0041]$. 


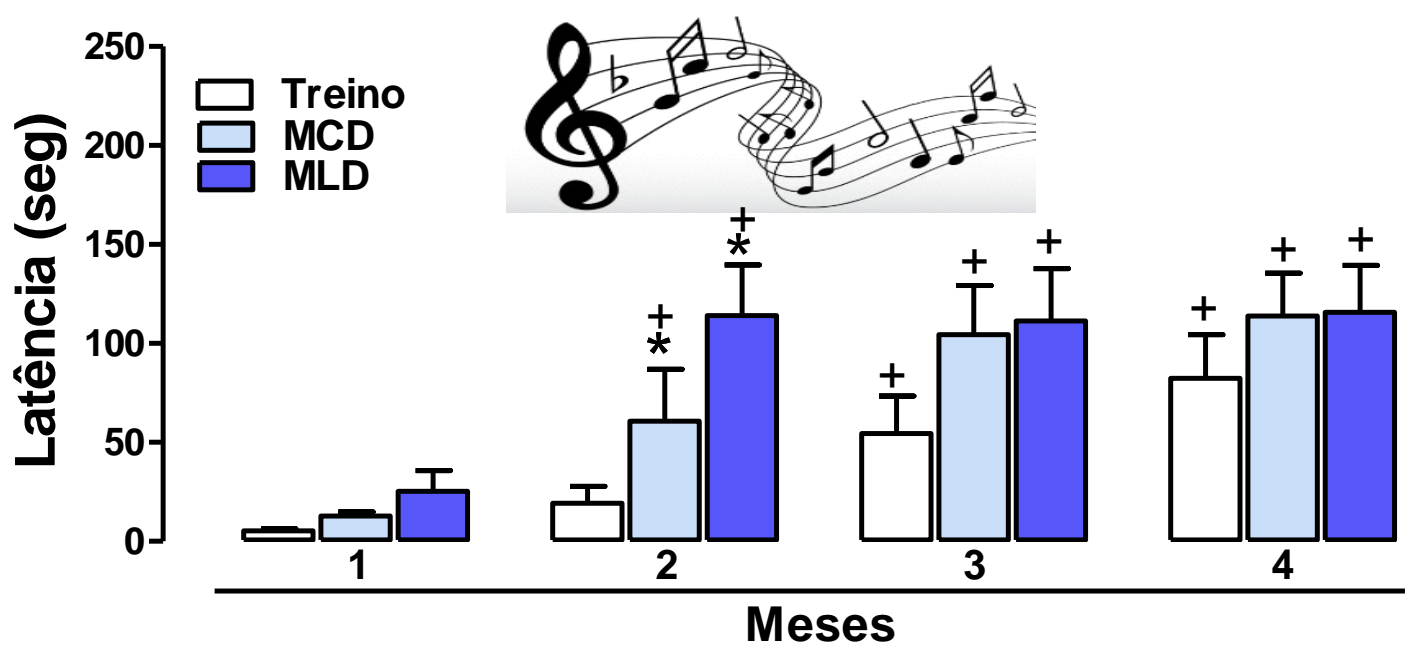

Figura 5 - Avaliação da aprendizagem/MCD e MLD de ratos com 1, 2, 3 ou 4 meses, no teste da esquiva inibitória após receberem a Sonata de Mozart 4h/dia, durante 4 dias que antecediam cada idade (grupo - G3). As avaliações em diferentes idades sempre eram repetidas com os mesmos animais. . $+p<0,05$ representa diferença estatística em relação aos treinos dos ratos com 1 mês de idade; ${ }^{*} p<0,05$ representa diferença estatística em relação ao treino de cada idade (ANOVA, Teste de Newman Keuls). MCD= Memória de curta duração; MLD= Memória de longa duração.

Posteriormente, foi considerada a importância de expor os ratos diariamente à Sonata de Mozart, sempre obedecendo aos mesmos horários de $2 \mathrm{~h}$ no turno matutino e $2 \mathrm{~h}$ no turno vespertino (exposição crônica). Na curva dependente da idade, observou-se resposta somente aos 4 meses de idade, tanto no treino $\left[\mathrm{F}_{(3,31)}=15,55 ; \mathrm{p}<0,0001\right]$, quanto na aprendizagem $/ \mathrm{MCD}$ $\left[\mathrm{F}_{(3,31)}=12,05 ; \mathrm{p}<0,0001\right]$ e $\operatorname{MLD}\left[\mathrm{F}_{(3,31)}=23,88 ; \mathrm{p}<0,0001\right]$. Na avaliação intragrupo foi observada diferença na aprendizagem/MCD e $\operatorname{MLD}\left[\mathrm{F}_{(2,23)}=8,279 ; \mathrm{p}=0,0042\right]$, conforme ilustrados na Figura 6.

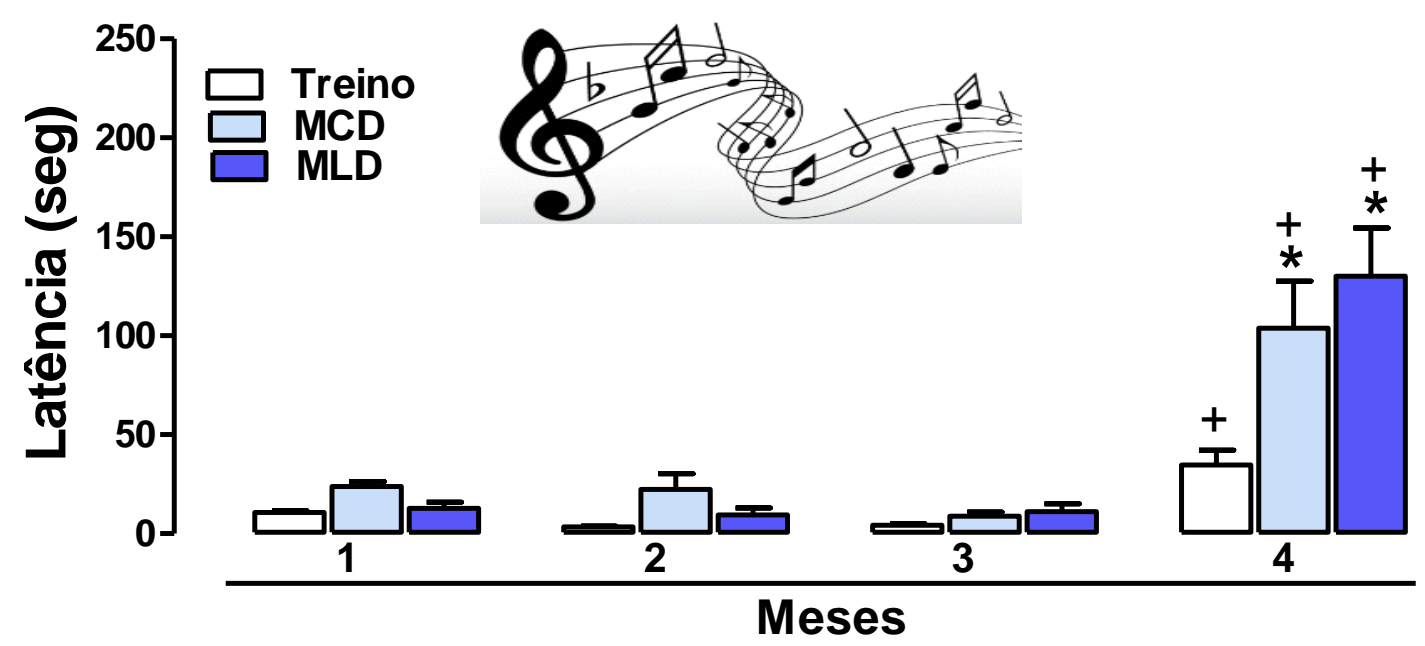

Figura 6 - Avaliação da MCD e MLD de ratos com 1, 2, 3 ou 4 meses, no teste da esquiva inibitória após receberem a Sonata de Mozart 4h/diariamente, durante 4 meses (grupo - G5). As avaliações em diferentes idades sempre eram repetidas com os mesmos animais. $+p<0,05$ representa diferença estatística em relação as respostas dos ratos com 1 mês de idade; ${ }^{*} p<0,05$ representa diferença estatística em relação ao treino dos ratos com 4 meses (ANOVA, Teste de Newman Keuls). MCD= Memória de curta duração; MLD= Memória de longa duração. 
Em um grupo complementar foi aplicado o NaNO2, com o objetivo de induzir $\mathrm{HI}$ aos 3 meses de idade. Observou-se que os controles que receberam NaNO2 deixaram de responder o tempo de latência na plataforma. Enquanto os sujeitos que receberam a Sonata de forma aguda mantiveram a resposta prévia $\left[\mathrm{F}_{(5,47)}=5.869 ; \mathrm{p}=0.0005\right]$, conforme Figura 7 .

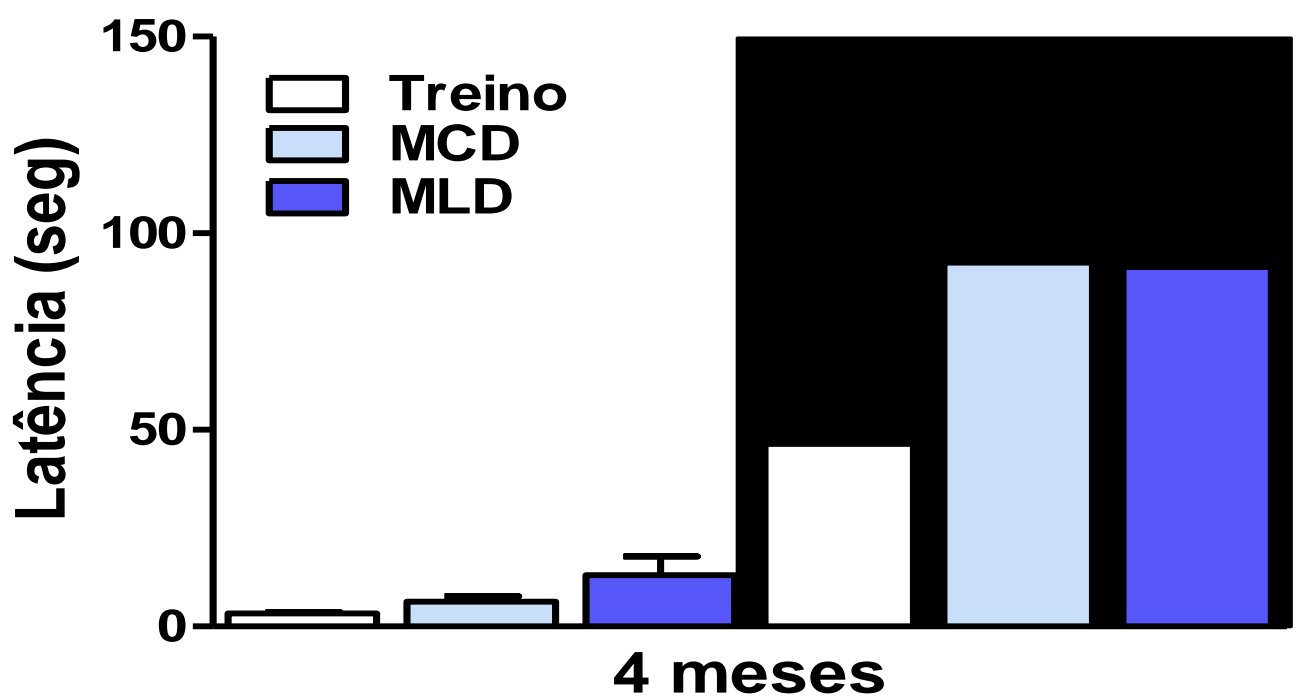

Figura 7 - Avaliação da aprendizagem/MCD e MLD de ratos com 4 meses de idade administrados com NaNO2 aos 3 meses de idade (grupo - G2) sem e com exposição à Sonata de Mozart durante 4h/dia, nos 4 dias que antecederam a idade de 4 meses (grupo - G4). Os símbolos musicais representam o grupo que recebeu a música. ${ }^{*} p<0,05$ representa diferença estatística em relação aos seus respectivos controles que não receberam a Sonata (ANOVA, Teste de Newman Keuls). MCD= Memória de curta duração; MLD= Memória de longa duração, $\mathrm{NaNO} 2=$ nitrito de sódio.

No entanto, quando a música foi dada de forma crônica e a HI induzida aos 3 meses de idade, observou-se que todos os grupos que receberam $\mathrm{NaNO} 2$ deixaram de responder o tempo de latência na plataforma da esquiva inibitória. A Sonata de Mozart exposta de forma crônica, por alguma razão, não protegeu os circuitos neurais afetados pelo NaNO2, interferindo de forma negativa nos resultados observados (Figura 8). 


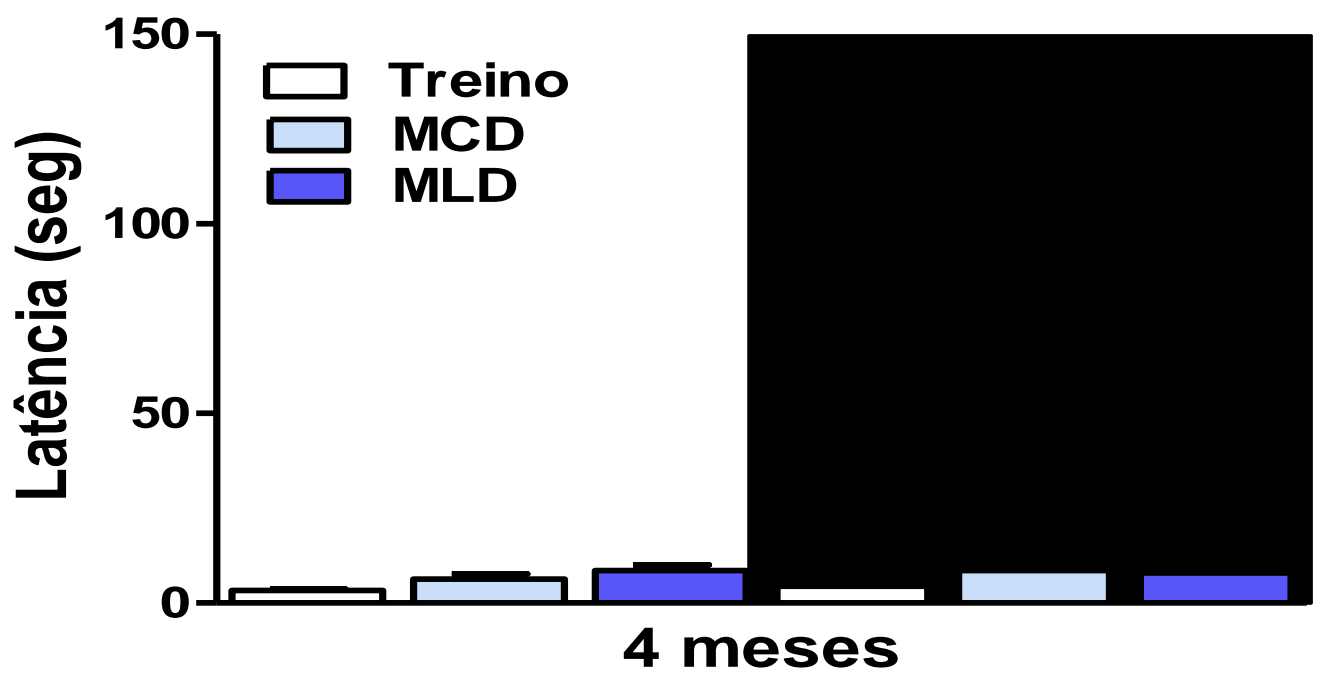

Figura 8 - Avaliação da aprendizagem/MCD e MLD de ratos com 4 meses de idade administrados com NaNO2 aos 3 meses de idade, sem e com exposição crônica à Sonata de Mozart 4h/dia, durante 4 meses (grupo - G6). Os símbolos musicais representam o grupo que recebeu a música. $\mathrm{MCD}=$ Memória de curta duração; $\mathrm{MLD}=$ Memória de longa duração, $\mathrm{NaNO} 2=$ nitrito de sódio. 


\section{DISCUSSÃO}

Com o presente estudo buscou-se investigar o potencial efeito protetor que a exposição à música poderia oferecer contra os déficits consequentes à $\mathrm{HI}$ induzida aos 3 meses nos ratos. Uma vez que provavelmente ocorreu lesão tecidual, o tratamento com a música, como fator estimulante à neuroplasticidade, poderia promover uma readaptação funcional das áreas lesadas de forma que não manifestassem extensos danos nas tarefas comportamentais.

Durante a avaliação, dois ensaios de retenção foram usados em cada animal, o primeiro 1 hora após o treino, para medir a aprendizagem/MCD e o segundo após 24 horas, para medir a MLD. O tempo que o animal permaneceu sobre a plataforma após a sessão de treino foi estabelecida como medida que permitiu inferir a ocorrência da aprendizagem. Quando a latência no teste foi maior que a de treino, inferiu-se que o animal recordou a exposição ao contexto aversivo (choque), ocorrendo assim a aprendizagem.

$\mathrm{O}$ interesse em avaliar roedores em diferentes fases de desenvolvimento, deveu-se ao fato de que resultados prévios do nosso grupo de pesquisa, complementados por aqueles observados no grupo do Prof. Dr. Pádua-Carobrez (Imhof et al., 1993), observaram resultados diferentes em comportamento dependentes da idade do sujeito experimental investigado. Ratos Wistar, machos e fêmeas em diferentes idades (45, 60, 90, 120 e 150 dias), tenderam a responder aos diferentes tipos de testes comportamentais, onde observaram que a idade mais avançada de desenvolvimento tendia a apresentar mais comportamentos sugestivos de medo e ansiedade, sugerindo uma diferença ontogenética nesses tipos de roedores. Também cabe aqui ressaltar que os mesmos estudos não demonstraram diferenças significativas entre sexos.

Nossos resultados mostraram que os sujeitos em diferentes idades de desenvolvimento (1 a 4 meses) responderam à aprendizagem/MCD e MLD quando avaliados no teste da esquiva inibitória do tipo "step down", demonstrando ser um instrumento confiável como medida de aprendizagem e memória. Quando os ratos foram expostos à Sonata de Mozart para dois pianos (K.448), o desempenho obtido no mesmo aparato foi dependente do tempo em que os animais tinham contato com a música, visto que o efeito da exposição aguda interferiu de forma significativa nos animais de 2 meses, quando a avaliação foi feita intragrupo. Em contrapartida, quando a avaliação foi realizada ao longo do desenvolvimento dos animais, as melhores observações da interferência da música foram vistas quando eles 
atingiram 3 e 4 meses de idade. A exposição crônica foi mais evidente nos animais com 4 meses, como demonstrado nas figuras 5 e 6 , respectivamente.

Todavia, não se descarta aqui a possibilidade das respostas terem sido influenciadas pelo processo de habituação à música, em decorrência dos ratos controles não terem tido a mesma resposta. Esses últimos quando expostos de forma repetida em diferentes fases de desenvolvimento, eles não alteraram a primeira resposta (ao choque) até os 3 meses, mantendo o mesmo limiar de resposta e com discreta alteração somente aos 4 meses. No entanto, quando observado os resultados dos animais controles com 3 e 4 meses de idade diante da exposição aguda da música, observou-se que eles responderam da mesma forma que as demais etapas de avaliações da MCD e MLD, sugerindo que talvez a Sonata contribuiu para a retenção da memória advinda das primeiras exposições, quando estavam com 1 e 2 meses de idade (figura 5).

É bem conhecido que diversas estruturas do SNC são formadas em diferentes fases do desenvolvimento. A migração celular é um importante processo que ocorre durante o desenvolvimento cerebral, onde os neurônios atingem um local-alvo. O contato entre essas células é importante para a formação dos circuitos neurais que interagem em todas as funções superiores. Esta circuitaria complexa, que envolve as comunicações entre as células nervosas, é responsável por todas as atividades que ocorrem no SNC. Quaisquer interferências com a migração celular, como a que ocorre pela presença de neurotóxicos, podem levar aos graves efeitos deletérios no desenvolvimento do cérebro (Castoldi et al., 2001; LoPachin \& Aschner,1993; Ransom, Behar \& Nedegaard, 2003).

Funções cognitivas são frequentemente comprometidas por lesão cerebral como a HI, podendo gerar consequências devastadoras a longo prazo. A lesão induzida por NaNo2 no presente estudo demonstrou-se sensível a disfunções do hipocampo e áreas adjacentes, e ainda foi possível observar déficits na aprendizagem e memória, provavelmente decorrente da lesão. Ao passo que, a exposição à Sonata de forma aguda protegeu, de alguma forma, contra a expansão destes déficits. O mesmo não foi observado diante da exposição crônica. Os resultados podem oferecer importantes perspectivas sobre a neuroplasticidade induzida pela música (Figuras 7 e 8).

O uso da música como método terapêutico tem sido interpretado como um facilitador de processos psicológicos, capaz de reduzir o estresse e controlar respostas emocionais. E 
ainda tem demonstrado resultados positivos em estudos que questionaram alterações neuroquímicas a algum tipo de tratamento musical (Bakker \& Martin, 2015; Hegde, 2014). Os resultados apresentados podem contribuir para o desenvolvimento de pesquisa sobre o os potenciais efeitos neuroprotetores de música em animais experimentais e humanos, com implicações importantes para a neuroplasticidade e reabilitação neurológica induzida pela música. As vantagens de tratamentos baseados em música é que eles são não invasivos e tem mínimo ou nenhum efeito colateral.

Mesmo que ainda não esteja claro como especificamente a música melhora a capacidade cognitiva, é provável que ela possa ser utilizada como uma ferramenta auxiliar para a tratamento de danos cerebrais. Deste modo, é possível abrir perspectivas importantes para a música como ferramenta de reabilitação, como possibilidade de compor novos tratamentos neuroprotetores, estendendo uma janela terapêutica, a fim de promover o ajustamento funcional. Faz-se necessário também esclarecer os mecanismos neurais subjacentes ao tratamento com música, a fim de compreender melhor os possíveis mecanismos neurofisiológicos do Efeito Mozart. E estabelecer relevância entre o modelo animal adotado como estratégia de estimulação a readaptação funcional de regiões lesadas.

Após o evento da HI, células são expostas a vários fatores de estresse, incluindo insuficiência energética, fluxo sanguíneo desequilibrado e estresse oxidativo. Por conseguinte, o desenho do presente modelo animal foi cuidadosamente adaptado para ser relevante para a literatura da música, cérebro e comportamento. Embora já seja bastante relatado na literatura, mais estudos de investigação terapêutica devem ser realizados para explorar os mecanismos de melhoria do uso terapêutico da música antes e/ou após a HI. Estudos futuros devem explorar mais as análises por microscopia de imunohistoquímica e eletrônica dos mecanismos neurais pelos quais a música protege funções cognitivas contra lesões por HI.

É importante enfatizar que um modelo experimental perfeito para uso com animais é isomórfico às condições humanas e que se torna útil quando mostrada uma analogia relevante, ou seja, quando o modelo revela alguns aspectos de um processo complexo através de hipóteses testadas em humanos (McBride \& Li, 1998). Através deles é possível realizar pesquisas celulares e moleculares, envolvendo neurotransmissores e receptores, que se constituem em ferramentas fundamentais para o estudo de muitos aspectos fisiológicos, farmacológicos, bioquímicos e comportamentais. 
Com os resultados desta pesquisa, conclui-se, de modo geral, que a exposição periódica da Sonata de Mozart para dois pianos (K. 448) pôde destacar-se como um instrumento interferente de forma positiva nas respostas comportamentais de ratos em diferentes fases de desenvolvimento. Deste modo, ao serem sugeridas novas perspectivas de intervenção com este método e aprimoramento do mesmo à ampliação da população de sujeitos, pode-se almejar tornar uma importante ferramenta de estimulação à neuroplasticidade, podendo atingir grande relevância para o desenvolvimento do cérebro e para a reabilitação neurológica. 


\section{CONCLUSÕES}

- A aprendizagem/MCD e MLD são processos importantes observados ao longo do desenvolvimento do SNC e dependente de informações prévias adquiridas nas primeiras idades de vida da amostra experimental.

- A Sonata de Mozart para dois pianos (K. 448) parece ser um estímulo importante para estimulação à plasticidade neuronal, visto que quando exposta de forma aguda é possível observar mudanças nas respostas cognitivas.

- Os eventos neuronais consequentes as prováveis lesões decorrentes da hipóxia isquêmica cerebral são passíveis de serem impedidos frente à exposição periódica (aguda) da Sonata de Mozart.

- A exposição da Sonata de Mozart de maneira crônica não demonstrou nenhum efeito neuroprotetor, uma vez que não houve obtenção de respostas esperadas nos testes de aprendizagem e memória. 


\section{$7 \quad$ PERSPECTIVAS FUTURAS}

Embora as pesquisas experimentais normalmente sofram limitações importantes, os dados obtidos e analisados não fornecem suporte preliminar para a afirmação de que a exposição à Sonata de Mozart para dois pianos (K. 448) medeiam mudanças neuroquímicas no funcionamento cognitivo. Para a obtenção de achados mais significantes e avanços nas áreas da cognição musical e neurociência nos estudos da neuroquímica, parece ser de grande relevância delinear novas abordagens de exploração:

$\checkmark$ Compreender e descrever melhor a circuitaria dos estímulos sonoros e seu processamento no cérebro;

$\checkmark$ Comparar a amostra selecionada a um grupo adicional em que ratos sejam expostos a outro ritmo musical;

$\checkmark$ Fragmentar os três movimentos da Sonata de Mozart, a fim de identificar se há diferenças significativas nos resultados comportamentais e morfofuncionais para cada movimento;

$\checkmark$ Analisar por microscopia de imunohistoquímica e eletrônica os mecanismos neurais pelos quais a música parece proteger funções cognitivas contra lesões por HI. 


\section{REFERÊNCIAS BIBLIOGRÁFICAS}

Amagdei, A., Baltes, F. R., Avram, J. \& Mil, A. C. (2010). Perinatal exposure to music protects spatial memory against callosal lesions. International Journal of Developmental Neuroscience, 28, 105-109.

Bakker, D. R. \& Martin, F. H. (2015). Musical chords and emotion: Major and minor triads are processed for emotion. Cognitive, Affective, \& Behavioral Neuroscience, 15,15-31.

Baky, N. A. A., Zaidi, Z. F., Fatani, A. J., Sayed-Ahmed, M. M., Yaqub, H. (2010). Nitric oxide pros and cons: The role of L-arginine, a nitric oxide precursor, and idebenone, a coenzyme-Q analogue in ameliorating cerebral hypoxia in rat. Brain Research Bulletin, $83,49-56$.

Bari, A., Dalley, J. W. \& Robbins, T. W. (2008). The application of the 5-choice serial reaction time task for the assessment of visual attentional processes and impulse control in rats. Nature, 3 (5), 759-67.

Beauvais, C. (2015). The 'Mozart Effect': A Sociological Reappraisal. Cultural Sociology, 9 (2), 185-202.

Cammarota, M., Bevilaqua, L. R. M., Rossato, J. I., Ramirez, M., Medina, J. H. \& Izquierdo, I. (2005). Relationship between short- and long-term memory and short- and long-term extinction. Neurobiology of Learning and Memory, 84, 25-32.

Carloni, S., Perrone, S., Buonocore, G., Longini, M., Proietti, F., Balduini, A. (2007). Melatonin protects from the long-term consequences of a neonatal hypoxic-ischemic brain injury in rats. Journal of Pineal Research, 44, 157-167.

Cassilhas, R. C., Tufik, S. \& de Mello, M. T. (2016). Physical exercise, neuroplasticity, spatial learning and memory. Cellular and Molecular Life Sciences, 73, 975-983.

Castoldi, A. F., Coccini, T., Ceccatelli, S., Manzo, L. (2001). Neurotoxicity and Molecular effects of methylmercury. Brain Research Bulletin, 55, 197-203. 
Chan, J. C. K. (2009). When does retrieval induce forgetting and when does it induce facilitation? Implications for retrieval inhibition, testing effect, and text processing. Journal of Memory and Language, 61, 153-170.

Chanda, M., L. \& Levitin, D. J. (2013). The neurochemistry of music. Trends in Cognitive Sciences, 17, 179-193.

Cheng, L., Wang, S., H., Chen, Q., C. \& Liao, X., M. (2011). Moderate noise induced cognition impairment of mice and its underlying mechanisms. Physiology Behavior 104, 981-988.

Chengzhi, C., Yan, T., Xuejun, J., Xiang, L., Youbin, Q., Baijie, T. (2011). Recovery of chronic noise exposure induced spatial learning and memory deficits in young male Sprague-Dawley rats. Journal of occupational health 53, 157-163.

Coppola, G., Toro, A., Operto, F. F., Ferrarioli, G., Pisano, S., Viggiano, A., Verrotti, A. (2015). Mozart's music in children with drug-refractory epileptic encephalopathies. Epilepsy \& Behavior, 50, 18-22.

Cui, B., Wu, M. \& She, X. (2009). Effects of chronic noise exposure on spatial learning and memory of rats in relation to neurotransmitters and NMDAR2B alteration in the hippocampus. Journal of occupational health 51, 152-158.

Deacon, R., M., Bannerman, D., M., Kirby, B., P., Croucher, A. \& Rawlins, J., N. (2002). Effects of cytotoxic hippocampal lesions in mice on a cognitive test battery. Behavioural Brain Research, 133, 57-68.

de los Angeles, G. A. M., del Carmen, R. O. M., Wendy, P. M., Socorro, R. M. (2016). Tactile stimulation effects on hippocampal neurogenesis and spatial learning and memory in prenatally stressed rats. Brain Research Bulletin, 124, 1-11.

du Plessis, A. J. \& Volpe, J. J. (2002). Perinatal brain injury in the preterm and term newborn. Current Opinion in Neurology, 15 (2), 151-157.

Dewi, E. K., Rusmawati, D. \& Ratnaningsih, I. Z. (2015). The Effect of Music and Motoric Movement Intervention to Increase Attention among Elementary School Studentsin Semarang Central Java. Procedia Environmental Sciences, 23, 179-185. 
Eichenbaum, H. (2004). Hippocampus: Cognitive Processes and Neural Representations that Underlie Declarative Memory. Neuron, 44, 109-120.

Emptage, N. J. \& Carew, T. J. (1993). Long-term synaptic facilitation in the absence of shortterm facilitation in Aplysia neurons. Science, 262, 253-256.

Erecinska, M. \& Silver, I. A. (2001). Tissue oxygen tension and brain sensitivity to hypoxia. Respiration Physiology, 128, 263-276.

Ferreri, L., Bigand, E. \& Bugaiska, A. (2015). The positive effect of music on source memory. Musicae Scientiae, 19 (4), 402-411.

Fields, R. D. (2010). Glutamate receptors: the cause or cure in perinatal white matter injury? Neuron Glia Biology, 6 (4), 209-211.

Fukui, H. \& Toyoshima, K. (2008). Music facilitate the neurogenesis, regeneration and repair of neurons. Medical Hypotheses, 71 (5), 765-769.

Ger, J., Kao, H., Shih, T. S., Deng, J. F. (1996). Fatal toxic methemoglobinemia due to occupational exposure to methyl nitrite. Journal of Clinical Medicine, 57, 78.

Gill, M. B. \& Perez-Polo, J. R. (2008). Hypoxia Ischemia-Mediated Cell Death in Neonatal Rat Brain. Neurochemical Research, 33, 2379-2389.

Girard, S., Murray, K. N., Rothwell, N. L., Metz, G. A., Allan, S. M. (2014). Long-term functional recovery and compensation after cerebral ischemia in rats. Behavioural Brain Research, 270, 18-28.

Gladwin, M. T., Crawford, J; H. \& Patel, R. P. (2004). The biochemistry of nitric oxide, nitrite, and hemoglobin: role in blood flow regulation. Journal of Free Radicals in Biology \& Medicine, 36, 707-717.

Hallet, M. (2001). Plasticity of the human motor cortex and recovery from stroke. Brain Research Reviews, 36, 169-174.

Hatem, T. P., Lira, P. I. \& Mattos, S. S. (2006). The therapeutic effects of music in children following cardiac surgery. Jornal de Pediatria, 82, 186-92. 
Hausmann, M., Hodgetts, S. \& Eerola, T. (2016). Music-induced changes in functional cerebral asymmetries. Brain and Cognition, 104, 58-71.

Hegde, S. (2014). Music-based cognitive remediation therapy for patients with traumatic brain injury. Frontiers in Neurology, 34 (5), 1-7.

Heim, S., Keil, A., Choudhury, N., Thomas Friedman, J., Benasich, A. A. (2013) Early gamma oscillations during rapid auditory processing in children with a language-learning impairment: changes in neural mass activity after training. Neuropsychologia 51, 9901001.

Hughes, J. R., Daaboul, Y., Fino, J., Shaw, G.L. (1998). The Mozart Effect on Epileptiform Activity, Clinical Electroencephalograph, 29 (3), 109-19.

Imhof, J. T., Coelho, Z. M. I., Schmitt, M. L., Morato, G. S., Carobrez, A. P. (1993). Influence of gender and age on performance of rats in the elevated plus maze apparatus. Behavioural Brain Research, 56, 177-180.

Izquierdo, I., Barros, D. M., Mello, T. S., de Souza, M. M. Izquierdo, L. A. \& Medina, J. H. (1998). Mechanisms for memory types differ. Nature, 393, 635-636.

Izquierdo, I., Cammarota, M., Vianna, M. R. \& Bevilaqua, L. R. (2004). The inhibition of acquired fear. Neurotoxicity Research, 6, 175-188.

Izquierdo, I. \& McGaugh, J. L. (2000). Behavioural pharmacology and its contribution to the molecular basis of memory consolidation. Behavior Pharmacology. 11, 517-534.

Izquierdo, I., Medina, J. H., Vianna, M. R., Izquierdo, L. A., Barros, D. M. (1999). Separate mechanisms for short- and long-term memory. Behavioural Brain Research, 103, 1-11.

Jyoti, S., Sushma, S., Shashi, S., Anjana, T. (2003). Protective effect of tulsi (Ocimum sanctum) on lipid peroxidation in stress induced by anemic hypoxia in rabbits. Indian Journal of Physiology and Pharmacology, 47 (1), 115-119.

Knaepen, K., Goekint, M., Heyman, E. M., Meeusen, R. (2010). Neuroplasticity exercise induced response of peripheral brain derived neurotrophic factor: a systematic review of experimental studies in human subjects. Journal of Sports Medicine, 40, 765-801. 
Kent, A. L., Wright, I. M., Abdel-Latif, M. E. (2012). Mortality and adverse neurologic outcomes are greater in preterm male infants. Pediatrics, 129 (1), 124-131.

Kim, H., Lee, M. H., Chang, H. K., Lee, T. H., Lee, H. H., Shin, M. C., (2006). Influence of prenatal noise and music on the spatial memory and neurogenesis in the hippocampus of developing rats. Brain and Development, 28 (2), 109-114.

Kim, D. S., Park, Y. G., Choi, J. H., Im, S. H., Jung, K. J., CHA, Y. A., Jung, C. O. \& Yoon, H. Y. (2011). Effects of Music Therapy on Mood in Stroke Patients. Yonsei Medical Journal, 52 (6), 977-981.

Kliewer, G. (1999). The Mozart Effect, New Scientist, 6, 35-7.

Kraus, N., Slater, J., Thompson, E. C., Hornickel, J., Strait, D. L., Nicol, T., White-Schwoch, T. (2014). Music Enrichment Programs Improve the Neural Encoding of Speech in AtRisk Children. The Journal of Neuroscience, 34 (36), 11913-11918.

Kroneisen, M., \& Erdfelder, E. (2011). On the plasticity of the survival processing effect. Journal of Experimental Psychology: Learning, Memory, and Cognition, 37(6), 15531562.

Krumhansl, C. L. (1997). An exploratory study of musical emotions and psychophysiology. Canadian Journal of Experimental Psychology, 51, 336-353.

Kumral, A., Uysal, N., Tugyan, K., Sonmez, A., Yilmaz, O., Gokmen, N., Kiray, M., Genc, S., Durman, N., Koroglu, T. F., Ozkan, H., Genc, K. (2004). Erythropoietin improves long-termspatialmemory deficits and brains injury following neonatal hypoxia-ischemia in rats. Behavioural Brain Research, 153, 77-86.

Lagasse, A. B. (2014). Effects of a Music Therapy Group Intervention on Enhancing Social Skills in Children with Autism. Journal of Music Therapy, doi: 10.1093 / JMT / thu012.

Leuner, B. \& Gould, E. (2010). Structural plasticity and hippocampal function. Annual Review of Psychology, 61,111-113.

Lin, L. C., Chiang, C. T., Lee, M. W., Mok, H. K., Yang, Y. H., Wu, H. C., Tsai, C. L., Yang, R. C. (2013). Parasympathetic activation is involved in reducing epileptiform discharges when listening to Mozart music. Clinical Neurophysiology, 124, 1528-1535. 
Lin, L. C. \& Yang, R. C. (2015). Mozart's music in children with epilepsy. Translational Pediatrics, 4 (4), 323-326.

Liu, L., Shen, P., He, T., Chang, Y., Shi, L., Tao, S., Li, X., Xun, Q., Guo, X., Yu, Z. \& Wang, J. (2016). Noise induced hearing loss impairs spatial learning/memory and hippocampal neurogenesis in mice. Nature, 6, 20734.

Lopachin, R. M. \& Aschner, M. (1993). Glial-neuronal interactions: the relevance to neurotoxic mechanisms. Toxicology and Applied Pharmacology, 118, 141-158.

Marsden, A. A. (1987). A Study of Cognitive Demands in Listening to Mozart's Quintet for Piano and Wind Instruments, K.452. Psychology of Music, 15, 30-57.

Martinez-Biarge, M., Diez-Sebastian, J., Kapellou, O., Gindner, D., Allsop, J. M., Rutherford, M. A., Cowan, F. M. (2011). Predicting motor outcome and death in term hypoxic ischemic encephalopathy. Neurology, 76 (24), 2055-2061.

McAuliffe, J. J., Loepke, A. W., Miles, L., Joseph, B., Hughes, E., Vorhees, C. V. (2009). Desflurane, isoflurane, and sevoflurane provide limited neuroprotection against neonatal hypoxia-ischemia in a delayed preconditioning paradigm. Anesthesiology, 111 (3), 53346.

McBride, W. J. \& Li, T. K. (1998). Animal models of alcoholism: neurobiology of high alcohol-drinking behavior in rodents. Critical Reviews in Neurobiology, 12, 339-369.

Mclean, C. \& Ferriero, D. (2004). Mechanisms of Hypoxic-Ischemic Injury in the Term Infant. Seminars in Perinatology, 28, 425-432.

Mcmahon, D. B. T. \& Barrionuevo, G., (2002). Short- and Long-Term Plasticity of the Perforant Path Synapse in Hippocampal Area CA3. Journal Neurophysiology, 88, 528533.

Mohr, J. P., Caplan, L. R., Melski, J. W. (1978). The Harvard cooperative stroke registry: a prospective registry, Neurology, 28, 754-762.

Nairne, J. S. \& Pandeirada, J. N. (2008). Adaptive memory: Is survival processing special? Journal of Memory and Language, 59 (3), 377-385. 
Newrzella, D., Pahlavan, P. S., Krüger, C., Boehm, C., Sorgenfrei, O., Schröck, H., Eisenhardt, G., Bischoff, N., Vogt, G., Wafzig, O., Rossner, M., Maurer, M. H. Hiemisch, H., Bach, A., Kuschinsky, W., Schneider, A. (2007). The functional genome of CA1 and CA3 neurons undernative conditions and in response to ischemia. BMC Genomics, 8, 370 .

Ortega, V. J., Casal, B. G., Garrido, E. \& Alcázar, B. (2004). Neuropsychological functioning associated with high-altitude exposure. Neuropsychology Review, 4 (4), 197-224.

Pagnussat, A. S., Faccioni-Heuser, M. C., Netto, C. A., Achaval, M. (2007). Na ultrastructural study of cell death in the CA1 pyramidal field of the hippocampus in rats submitted to transiente global ischemia followed by reperfusion. Physiological Mini-Reviews, 2 (4), 589-599.

Perlman, J. M. (2004). Brain injury in the term infant. Seminars in Parinatology, 28 (6), 415 24.

Perlovsky, L., Cabanac, A., Bonniot-Cabanac, M. C., Cabanac, M. (2013). Mozart effect, cognitive dissonance, and the pleasure of music. Behavioural Brain Research, 244, 9-14.

Ransom, B., Behar, T. \& Nedegaard, M. (2003). New roles for astrocytes (stars at last). Trends in Neurosciences, 26, 620-622.

Rauscher, F. H., Shaw, G. L. \& Ky, K. N. (1993). Music and Spatial Task Performance, Nature, $365,611$.

Rauscher, F. H., Shaw, G. L. \& Ky, K. N. (1995). Listening to Mozart enhances spatialtemporal reasoning: towards a neurophysiological basis. Neuroscience Letters, 185, 4447.

Rideout, B. E. \& Laubach, C. M. (1996). EEG Correlates of Enhanced Spatial Performance Following Exposure to Music, Perceptual and Motor Skills, 82, 427-32.

Sarkamo, T., Tervaniemi, M., Laitinen, LicPhil, S. L., Numminen, A., Kurki, M., Johnson, J. K., Rantanen, P. (2013). Cognitive, Emotional, and Social Benefits of Regular Musical Activities in Early Dementia: Randomized Controlled Study. The Gerontologist, 54 (4), $634-650$. 
Schlett, K. (2006) Glutamate as a modulator of embryonic and adult neurogenesis. Current Topics In Medicinal Chemistry, 6, 949-60.

Shalak, L. \& Perlman, J. M. (2004). Hypoxic-ischemic brain injury in the term infant-current concepts. Early Human Development, 80, 125-141.

Smith, A. L., Alexander, M., Rosenkrantz, T. S., Sadek, M. \& Fitch, R. H. (2014). Sex differences in behavioral outcome following neonatal hypoxia ischemia: Insights from a clinical meta-analysis and a rodent model of induced hypoxic ischemic brain injury. Experimental Neurology, 254, 54-67.

Strait, D. L., O’Connell, S., Parbery-Clark, A., Kraus, N. (2014). Musicians' Enhanced Neural Differentiation of Speech Sounds Arises Early in Life: Developmental Evidence from Ages 3 to 30. Cerebral Cortex, 24, 2512-2521.

Sun, M. K. \& Alkon, D. L. (2001). Pharmacological enhancement of synaptic efficacy, spatial learning, and memory through carbonic anhydrase activation in rats. Journal of Pharmacology and Experimental Therapeutics, 24, 222-228.

Tasset, I., Quero, I., García-Mayórgaz, A. D., Del Río, M. C., Túnez, I., Montilla, P. (2012) Changes caused by haloperidol are blocked by music in Wistar rat. Journal of Physiology and Biochemistry, 68, 175-179.

Verrusio, W., Ettorre, E., Vicenzini, E., Vanacore, N., Cacciafesta, M., Mecarelli, O. (2015). The Mozart Effect: A quantitative EEG study. Consciousness and Cognition, 35, 150155.

Xing, Y., Qin, Y., Jing, W., Zhang, Y., Wang, Y., Guo, D., Xia, Y., Yao, D. (2016). Exposure to Mozart music reduces cognitive impairment in pilocarpine-induced status epilepticus rats. Cognitive Neurodynamics, 10, 23-30.

Zaidi, Z. F. (2010). Periportal Necrosis in Rat Liver Exposed to Sodium Nitrite-induced Hypoxia. Journal of Animal and Veterinary Sciences, 5 (2), 111-116.

Zatorre, R. J. \& Salimpoor, V. N. (2013). From perception to pleasure: Music and its neural substrates. Proceedings of the National Academy of Sciences, 110, 10430-10437.

Zhang, Q., Wei, E. Q., Zhu, C. Y., Zhang, W. P., Wang, M. L., Zhang, S. H., Yu, Y. P., Chen, 
Z. (2006). Focal cerebral ischemia alters the spatio-temporal properties, but not the amount of activity in mice. Behavioural Brain Research, 169, 66-74.

Zhu, X., Wang, F., Hu, H., Sun, X., Kilgard, M. P., Merzenich, M. M., Zhou, X. (2014). Environmental acoustic enrichment promotes recovery from developmentally degraded auditory cortical processing. Journal Neuroscience, 34, 5406-5415.

Zhu, W., Zhao, L., Zhang, J., Ding, X., Liu, H., Ni, E., Ma, Y. \& Zhou, C. (2008). The influence of Mozart's sonata K.448 on visual attention: An ERPs study. Neuroscience Letters, 434, 35-40. 
ANEXOS

- Pareceres da Comissão de Ética no Uso Animal (CEUA) 2013 e 2014.

Universidade de Brasilia

Instituto de Cièncias Biológicas
Comite de Etica no Uso Animal

Brasilia, 08 de novembro de 2013.

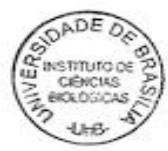

DECLARAÇĀO

Declaramos que o projeto intitulado "INFLuênCIA DA MusicoterAPIA No SISTEMA NERVoso EM DESENVOLVIMENTO: UMA AVALIAÇ̄̃o EXPERIMENTAL", UnBDOC n. $90243 / 2013$, sob responsabilidade da Professora Vânia Moraes Ferreira foi avaliado e aprovado pela Comissão de Ética no Uso Animal (CEUA) do Instituto de Ciências Biológicas da Universidade de Brasilia.
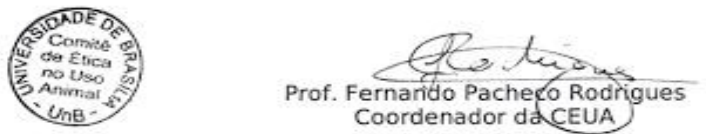

-Este documento se restringe da avałaçå etica do projeto suprackado e năo substitui outras licenças e permissbes que porventura se facam necessărias.

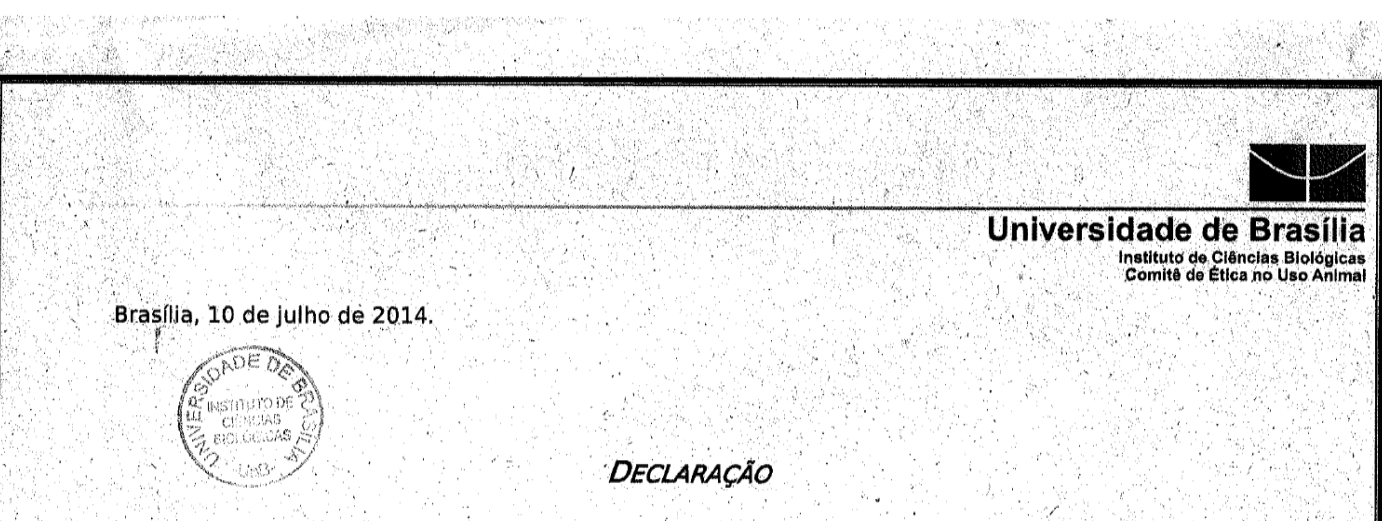

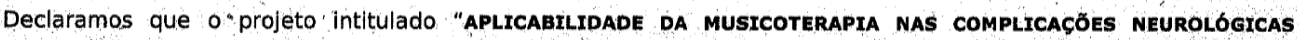

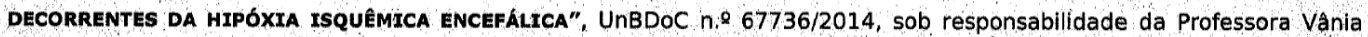
Ferreira foi avaliado e aprovado pela Comissão de Ética no Uso Animal (CEUA) do Instituto de Cléncias Biológicas da Universidade de Brasillia.
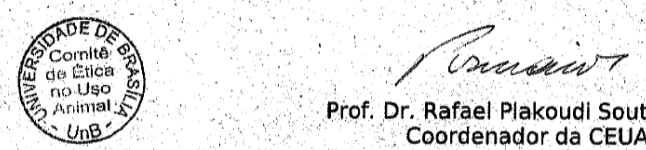
Prof. Dr. Rafael Plakoudi Souto Maior
Coordenador da CEUA

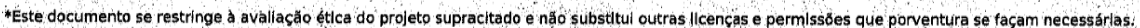

